\title{
Multidisciplinary Approaches for Transthyretin Amyloidosis
}

\author{
Haruki Koike (D) - Takahiro Okumura - Toyoaki Murohara • \\ Masahisa Katsuno
}

Received: April 10, 2021 / Published online: June 4, 2021

(C) The Author(s) 2021

\section{ABSTRACT}

Amyloidosis caused by systemic deposition of transthyretin (TTR) is called ATTR amyloidosis and mainly includes hereditary ATTR (ATTRv) amyloidosis and wild-type ATTR (ATTRwt) amyloidosis. Until recently, ATTRv amyloidosis had been considered a disease in the field of neurology because neuropathic symptoms predominated in patients described in early reports, whereas advances in diagnostic techniques and increased recognition of this disease revealed the presence of patients with cardiomyopathy as a predominant feature. In contrast, ATTRwt amyloidosis has been considered a disease in the field of cardiology. However, recent studies have suggested that some of the patients with ATTRwt amyloidosis present tenosynovial tissue complications, particularly carpal tunnel syndrome, as an initial manifestation of amyloidosis, necessitating an awareness of this disease among neurologists and orthopedists. Although histopathological confirmation of amyloid deposits has traditionally been considered mandatory for the diagnosis of

H. Koike $(\varangle) \cdot$ M. Katsuno

Department of Neurology, Nagoya University Graduate School of Medicine, Nagoya, Japan e-mail: koike-haruki@med.nagoya-u.ac.jp

T. Okumura · T. Murohara

Department of Cardiology, Nagoya University

Graduate School of Medicine, Nagoya, Japan
ATTR amyloidosis, the development of noninvasive imaging techniques in the field of cardiology, such as echocardiography, magnetic resonance imaging, and nuclear imaging, enabled nonbiopsy diagnosis of this disease. The mechanisms underlying characteristic cardiac imaging findings have been deciphered by histopathological studies. Novel disease-modifying therapies for ATTR amyloidosis, such as TTR stabilizers, short interfering RNA, and antisense oligonucleotides, were initially approved for ATTRv amyloidosis patients with polyneuropathy. However, the indications for the use of these disease-modifying therapies gradually widened to include ATTRv and ATTRwt amyloidosis patients with cardiomyopathy. Since the coronavirus disease 2019 (COVID-19) pandemic, which is caused by severe acute respiratory syndrome coronavirus 2 (SARS-CoV-2) infection, occurred, the minimization of hospital visits and telemedicine have become increasingly important. As older age and cardiovascular disease are major factors associated with increased disease severity and mortality of COVID-19, many ATTR amyloidosis patients are at increased risk of disease aggravation when they are infected with SARSCoV-2. From this viewpoint, close interspecialty communication to determine the optimal interval of evaluation is needed for the management of patients with ATTR amyloidosis. 
Keywords: Amyloid angiopathy; Cardiac amyloidosis; Inotersen; Positron emission tomography; Patisiran; Protein misfolding disease; Red flag; Scintigraphy; Tafamidis; Treatment

\section{Key Summary Points}

ATTR amyloidoses mainly includes ATTRv amyloidosis and ATTRwt amyloidosis based on the presence and absence of TTR mutations, respectively.

Until recently, ATTRv amyloidosis has been considered a disease in the field of neurology, whereas ATTRwt amyloidosis has classically been regarded as a disease in the field of cardiology.

Although a histopathological confirmation of amyloid deposits has traditionally been required for the diagnosis of ATTR amyloidosis, the development of noninvasive imaging techniques enabled nonbiopsy diagnosis of this disease.

Although novel disease-modifying therapies for ATTR amyloidosis, such as TTR stabilizers and gene silencing agents, were initially approved for ATTRv amyloidosis patients with polyneuropathy, the indications for the use of these novel disease-modifying therapies gradually widened to include ATTRv and ATTRwt amyloidosis patients with cardiomyopathy.

As older age and cardiovascular disease are major factors associated with increased disease severity and mortality of COVID-19, many ATTR amyloidosis patients are at increased risk of disease aggravation when they are infected with SARS-CoV-2.

Close interspecialty communication to determine the optimal interval of evaluation is needed for the management of patients with ATTR amyloidosis.

\section{DIGITAL FEATURES}

This article is published with digital features, including a summary slide, to facilitate understanding of the article. To view digital features for this article go to https://doi.org/10.6084/ m9.figshare.14579922.

\section{INTRODUCTION}

Amyloidosis is caused by the deposition of amyloid fibrils composed of misfolded protein in various organs. Transthyretin (TTR), which is mainly produced in the liver and functions as a transporter of thyroxin (T4) and retinol-binding protein, is one of the more than 30 amyloidogenic proteins reported to date [1]. Amyloidosis caused by systemic deposition of TTR is now designated ATTR amyloidosis and mainly consists of hereditary ATTR (ATTRv; $v$ for variant) amyloidosis and wild-type ATTR (ATTRwt) amyloidosis based on the presence and absence of TTR mutations, respectively [2, 3]. Although rare, ATTR amyloidosis has also been reported in recipients of livers from ATTRv amyloidosis patients [3]. ATTRv amyloidosis was first reported in 1952 in Portugal and was subsequently reported in endemic areas of Japan and Sweden [4-6]. Until recently, ATTRv amyloidosis was considered a disease in the field of neurology and called familial amyloid polyneuropathy because neuropathic symptoms predominated in patients described in early reports [3]. However, advances in diagnostic techniques and increased recognition of this disease revealed that ATTRv amyloidosis was prevalent even in areas other than conventional endemic foci and focused on the presence of patients with cardiomyopathy as a predominant feature [7-9]. In contrast, ATTRwt amyloidosis has classically been called senile cardiac or systemic amyloidosis because it is considered a cardiomyopathy found in elderly individuals [10]. The recent development of noninvasive diagnostic tools, such as ultrasonography, magnetic resonance imaging, and nuclear imaging, enables the early diagnosis of cardiomyopathy resulting from ATTRwt amyloidosis [11, 12]. In addition, recent studies have suggested that some of the 
patients with ATTRwt amyloidosis present tenosynovial tissue complications, particularly carpal tunnel syndrome [13-15]. Other studies have also suggested an association between wild-type TTR deposition in the ligaments and spinal canal stenosis [16, 17]. These findings indicate that even neurologists and orthopedists should consider the possibility of ATTRwt amyloidosis when they encounter patients complaining of numbness or pain in the limbs in daily clinical practice.

Due to the progress in novel disease-modifying therapies for ATTR amyloidosis, such as TTR stabilizers, short interfering RNA (siRNA), and antisense oligonucleotides (ASOs), early diagnosis and better management to maintain patients' quality of life are required [1, 3]. Therefore, the necessity of close cooperation among multiple departments, particularly neurology and cardiology, is increasing $[18,19]$. In this review, we describe recent developments in the diagnosis and management of ATTR amyloidosis, focusing on an increased necessity of multidisciplinary approaches. This article is based on previously conducted studies and does not contain any studies with human participants or animals performed by any of the authors.

\section{CHARACTERISTICS OF ATTR AMYLOIDOSIS}

\section{ATTRv Amyloidosis}

Although TTR is stable as a homotetramer, the dissociation of tetramers into monomers causes the misfolding of this protein, resulting in the aggregation of TTR into amyloid fibrils $[20,21]$. Most TTR mutations result in the production of variant TTR that is less stable than wild-type TTR, leading to the dissociation of this protein [22]. Patients from conventional endemic foci in Portugal, Japan, and Sweden have the Val30Met mutation (p.Val50Met, according to the Human Genome Variation Society recommendation) [1]. As many patients with the Val30Met mutation have also been found in nonendemic areas [23, 24], this mutation was considered to be the most common among
ATTRv amyloidosis patients predominantly manifesting polyneuropathy. ATTRVal30Met amyloidosis patients from endemic foci in Japan and Portugal are characterized by an early age of disease onset, ranging from the late 20 s to early 40s [4, 23]. By contrast, many patients with later disease onset are found in Sweden despite having the same mutation [6]. Patients from nonendemic areas are characterized by late onset of the disease, usually after 50 years of age [23]. As patients with the Val30Met mutation predominantly manifest somatic and autonomic neuropathies [8], mainly neurologists have been involved in the diagnosis and management of this disease.

By contrast, the development of diagnostic techniques led to the discovery of many patients with mutations other than Val30Met (i.e., non-Val30Met mutations), and more than 130 non-Val30Met mutations have been reported [1]. Cardiomyopathy may be the predominant feature in patients with some of the nonVal30Met mutations $[9,25]$. For example, the Val122Ile (p.Val142Ile) mutation is considered a common cause of heart disease in African Americans originating from West African countries [26, 27]. A number of Caucasian patients with the Val122Ile mutation have also been found in Italy [28]. Currently, this mutation, rather than Val30Met mutation, is considered to be the most common among ATTRv amyloidosis patients worldwide [26]. Hence, cardiologists have recently paid attention to this disease.

\section{ATTRwt Amyloidosis}

The dissociation and subsequent aggregation of TTR are considered to occur even under physiological conditions, leading to the occurrence of wild-type TTR deposition [21, 29]. In addition, an alternative pathway resulting from proteolytic cleavage of TTR has been proposed for the process of amyloid fibril formation in patients with ATTR amyloidosis [30]. Amyloid deposits from ATTR amyloidosis patients contain a significant amount of C-terminal fragments [31, 32].

As opposed to ATTRv amyloidosis, ATTRwt amyloidosis has traditionally been regarded as a disease in the field of cardiology rather than 
neurology because cardiomyopathy is the predominant feature of this disease [10]. Studies of autopsy specimens suggested that a significant proportion of the elderly population, particularly elderly males, has TTR deposition in the heart even in subjects without a history of underlying diseases [10, 33, 34]. Currently, cardiomyopathy resulting from ATTRwt amyloidosis is an important differential diagnosis of heart failure with preserved ejection fraction $[35,36]$.

In addition to cardiomyopathy, ATTRwt amyloidosis may also present features suggestive of carpal tunnel syndrome that frequently precede those of cardiomyopathy [13]. Analyses of tenosynovial tissues obtained during carpal tunnel release surgery revealed that a significant proportion of patients diagnosed with idiopathic carpal tunnel syndrome had TTR amyloid deposits [37-40]. This finding raises the necessity of an awareness of ATTRwt amyloidosis even among orthopedists and neurologists. In particular, the possibility of having ATTRwt amyloidosis becomes higher in elderly male patients with bilateral carpal tunnel syndrome [15]. Furthermore, an association between spinal canal stenosis and wild-type TTR deposition in ligaments has also been suggested $[17,40,41]$. A recent study suggested that even brachial biceps tendon rupture is one of the red flags of ATTR amyloidosis [14].

\section{DIAGNOSIS}

\section{General Considerations}

Polyneuropathy usually involves symmetric sensory and motor deficits in the distal portions of extremities resulting from endoneurial amyloid deposition [42]. In addition, autonomic symptoms, such as diarrhea, constipation, orthostatic intolerance, dysuria, and erectile dysfunction, are frequently reported, particularly in patients from conventional endemic foci $[1,23]$. Hence, sensorimotor polyneuropathy accompanied by autonomic symptoms is an important feature suggestive of, although not specific to, amyloid neuropathy [24]. The presence of polyneuropathy is confirmed by nerve conduction studies [43]. Although axonal neuropathy indicated by reduced compound muscle action potentials and sensory nerve action potentials is the cardinal feature of polyneuropathy, findings suggestive of demyelination, such as the slowing of conduction velocities and the prolongation of distal motor latencies, are also concomitantly found in some cases $[43,44]$. Other methods for assessing polyneuropathy include quantitative sensory testing and measuring skin innervation using skin biopsy specimens [45-47].

Amyloid deposition in the heart results in diastolic dysfunction and causes symptoms of heart failure, such as fatigue, palpitation, and dyspnea $[8,9]$. In daily clinical practice, chest $\mathrm{X}$-ray, electrocardiogram, echocardiography, and plasma levels of brain natriuretic peptide (BNP) or N-terminal prohormone of BNP (NTproBNP) are used to validate the presence of cardiomyopathy $[1,8]$. Cardiac troponins, including troponin $\mathrm{T}$ and troponin $\mathrm{I}$, can also be used as markers to evaluate cardiomyopathy in patients with ATTR amyloidosis [48]. Heart failure with preserved ejection fraction is the characteristic feature of cardiomyopathy resulting from amyloidosis $[35,36]$. On electrocardiogram, low voltage and abnormal $\mathrm{Q}$ waves called pseudoinfarct patterns may be observed [49]. As conduction disorders frequently occur as a result of cardiomyopathy [42], Holter electrocardiography is required to consider the indication for pacemaker implantation [1]. Notably, syncope in ATTRv amyloidosis patients results from not only cardiac conduction disorders but also orthostatic hypotension associated with autonomic dysfunctions $[25,50]$.

Representative ref flags for ATTR amyloidosis are shown in Table 1. Based on these findings, further assessments, such as more specific imaging studies, biopsy to detect amyloid deposits, and TTR gene sequencing, are considered for the confirmation of the diagnosis of ATTR amyloidosis. 
Table 1 Representative red flags for ATTR amyloidosis

For neurologists

Carpal tunnel syndrome (bilateral)

Sensorimotor polyneuropathy and at least one of the following findings ${ }^{a}$

Positive family history

Cardiac symptoms

Autonomic symptoms

Diarrhea/constipation

Orthostatic intolerance/syncope

Dysuria

Unexplained weight loss

Ocular symptoms (vitreous opacities)

For cardiologists

Heart failure with preserved ejection fraction and at least one of the following findings

Polyneuropathy ${ }^{a}$

Positive family history ${ }^{a}$

Carpal tunnel syndrome

Characteristic electrophysiology and imaging findings ${ }^{\mathrm{b}}$

Electrocardiogram

Low voltage in the limb leads

Abnormal Q waves (pseudoinfarct pattern)

Echocardiography

Thickened left ventricular wall and interventricular septum

Hyperrefractile myocardial echoes (granular sparkling appearance)

${ }^{a}$ Only applied to ATTRv amyloidosis

b Only conventional findings are shown here

\section{Biopsy}

The detection of amyloid deposits in biopsy specimens has traditionally been required for the formal diagnosis of ATTR amyloidosis [1]. Congo red staining is useful to detect amyloid deposits in daily clinical practice. Amyloid is stained as congophilic deposits on light microscopy and appears as green (or apple-green) birefringence when examined with polarized light $[2,51]$. Fibrillar structures, the morphological characteristics of amyloid, are confirmed by electron microscopy [52]. These amyloid fibrils affect neighboring tissues, resulting in organ dysfunction [42, 52]. Previous studies demonstrated the deposition of oligomeric nonfibrillar TTR in biopsy or autopsy specimens of the peripheral nerve [42, 52]. The toxicity of such precursors of amyloid fibrils to surrounding tissues has also been suggested [53]. 
As amyloid deposition occurs systemically in ATTR amyloidosis patients, organs other than peripheral nerves and the heart can be considered the target for biopsy, taking accessibility into consideration. These organs include the labial minor salivary gland, gastrointestinal tract mucosa, and skin [1]. Abdominal fat aspiration biopsy is also frequently performed in Japan because it enables repetitive examination even for asymptomatic carriers [54].

Immunohistochemistry of amyloid deposits is important to distinguish TTR from other proteins that may cause amyloidosis, particularly immunoglobulin light chain associated with light chain (AL) amyloidosis [55]. Mass spectrometry is also useful to determine the specific amyloid-forming protein in tissue samples [56-58].

\section{Ultrasonography}

Echocardiography is a noninvasive technique that enables repetitive assessment of cardiac morphology and function. The thickening of the left ventricular wall and interventricular septum accompanied by hyperrefractile myocardial echoes (i.e., a granular sparkling appearance) have traditionally been recognized as the characteristics of cardiac amyloidosis (Fig. 1) [49]. As amyloid deposition in the extracellular spaces of cardiomyocytes causes left ventricular diastolic dysfunction, tissue Doppler imaging shows reduced diastolic velocities and an increased E/e' ratio [59]. Massive amyloid deposition in ventricular walls results in heart failure with preserved ejection fraction $[35,36]$.

Tissue Doppler strain imaging and strain-rate imaging are useful to detect early left ventricular longitudinal systolic dysfunction that cannot be detected by conventional tissue Doppler imaging in patients with $\mathrm{AL}$ amyloidosis $[60,61]$. Although these methods may also be applied in patients with ATTR amyloidosis, a study that compared the results of AL amyloidosis patients with those of ATTRv amyloidosis patients suggested that the extent of abnormalities was less in ATTRv amyloidosis patients from a conventional endemic focus in Japan
[62], which may be explained by the lower amount of cardiac amyloid deposits in this type of ATTR amyloidosis [42]. Two-dimensional speckle-tracking strain imaging can demonstrate reduced left ventricular strain in the middle and basal segments with relatively preserved strain in the apex $[63,64]$. This finding is called apical sparing, which is a characteristic feature in cardiac amyloidosis, including ATTR amyloidosis (Fig. 2).

Ultrasonography has also been applied to sites other than the heart. Although not specific, an enlargement of cross-sectional areas of the nerve trunk, particularly at proximal sites, was reported in ATTRv amyloidosis patients $[65,66]$. Additionally, a study of abdominal fat ultrasonography suggested the usefulness of B-mode images for in screening ATTRv amyloidosis [67].

\section{Magnetic Resonance Imaging}

Recent studies have demonstrated the usefulness of cardiac magnetic resonance imaging (MRI) for the diagnosis of cardiac amyloidosis, including ATTR amyloidosis [11]. Late gadolinium enhancement (LGE) is a highly sensitive and specific finding associated with myocardial amyloid deposition (Fig. 3) [68, 69]. LGE transfers from the subendocardial pattern to the transmural pattern as the disease progresses [70]. As LGE tends to be more conspicuous in patients with ATTR amyloidosis than in those with AL amyloidosis, transmural patterns of LGE are more frequently seen in ATTR amyloidosis patients [71]. LGE may be associated with microangiopathy that enhances the leakage of serum components from the lumina of vessels (Fig. 4) [72]. This hypothesis is supported by myocardial T2 mapping, an MRI technique used to demonstrate myocardial edema [73].

Myocardial T1 mapping, including native T1 (Fig. 5) and the measurement of extracellular volume using contrast-enhanced imaging, is a method to quantitatively evaluate $\mathrm{T} 1$ relaxation time influenced by amyloid deposits [74, 75]. A study of ATTRv amyloidosis patients suggested that the sensitivity of T1 mapping to detect cardiac amyloidosis is higher than that of LGE 

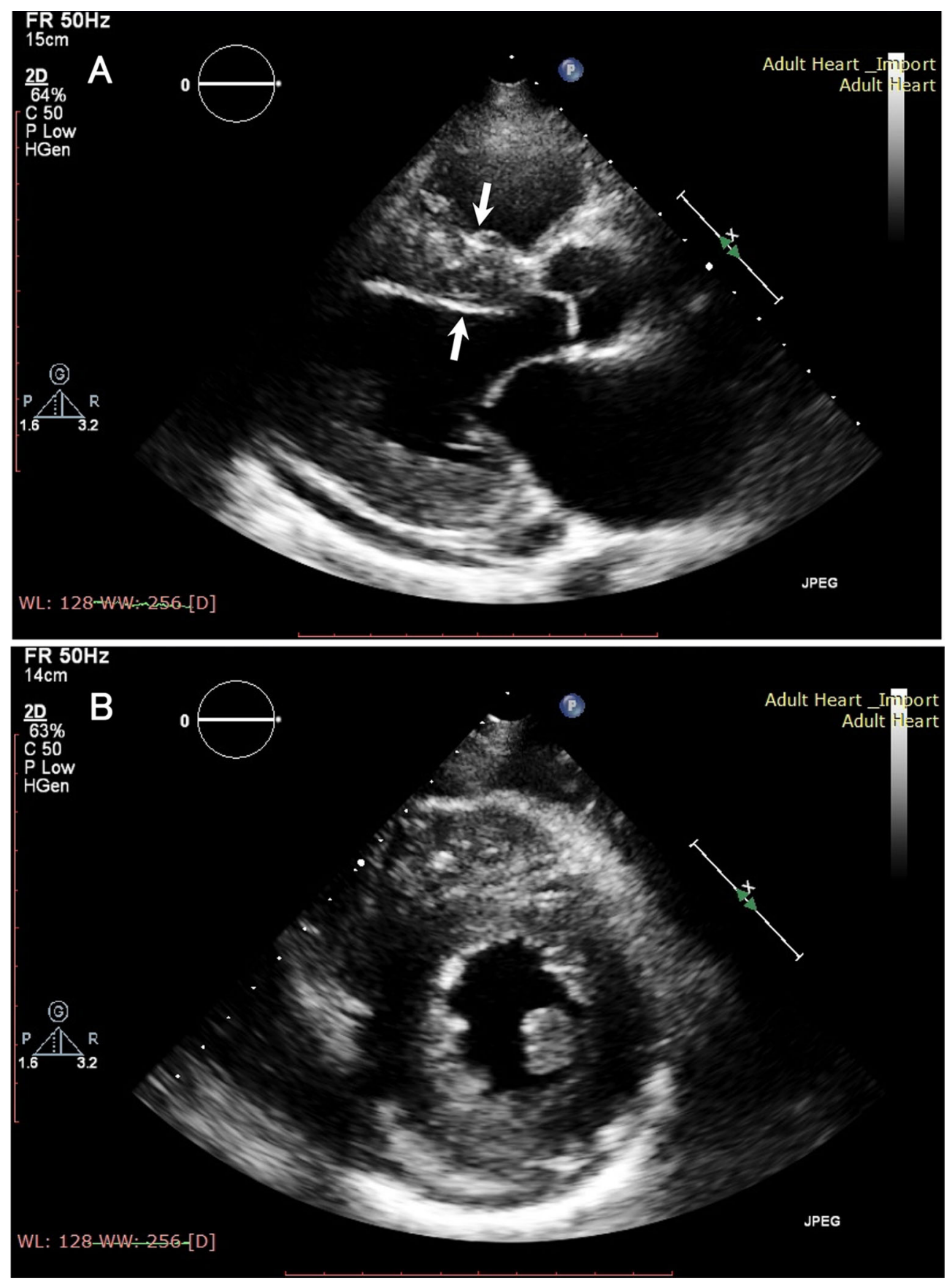

Fig. 1 Representative B-mode echocardiography findings of ATTR amyloidosis. a A thickened interventricular septum with hyperrefractile myocardial echoes (i.e., a

[76]. Extracellular volume in ATTR amyloidosis patients can also be calculated by dynamic equilibrium or dual-energy computed tomography $[77,78]$. granular sparkling appearance) is observed in the long-axis view (arrows). b Concentric hypertrophy of the ventricular wall is demonstrated in the short-axis view

As described earlier, the usefulness of strain imaging for the diagnosis of cardiac amyloidosis has been established by ultrasonography techniques. Myocardial strain analysis by cardiac 


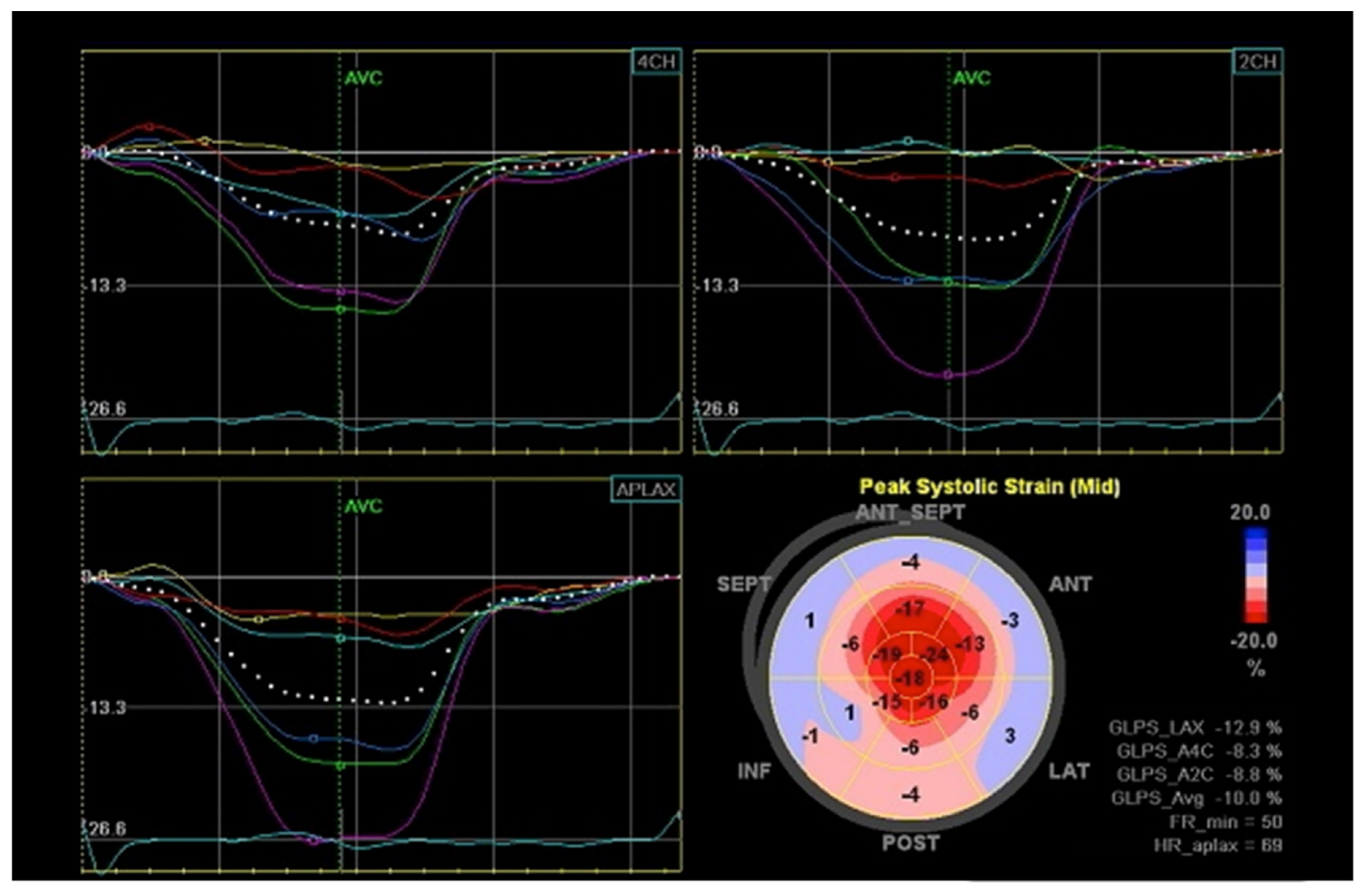

Fig. 2 Two-dimensional speckle-tracking strain imaging of echocardiography in a late-onset ATTRVal30Met amyloidosis patient from a nonendemic area of Japan. Reduced left ventricular longitudinal strain in the middle

MRI has also been demonstrated to help diagnose cardiomyopathy in ATTR amyloidosis patients [76]. Finally, a recent study suggested the utility of diffusion tensor imaging for the detection of cardiac amyloidosis, including ATTR amyloidosis [79].

MRI has also been applied to detect neuropathy in ATTRv amyloidosis patients [80, 81]. Magnetic resonance neurography studies have demonstrated peripheral nerve lesions even in asymptomatic carriers [80, 81]. However, the specificity of the findings obtained by magnetic resonance neurography has not yet been clarified.

\section{Nuclear Imaging}

The importance of scintigraphy to detect cardiac uptake of bone tracers, such as ${ }^{99 \mathrm{~m}} \mathrm{Tc}-3,3-$ and basal segments with relatively preserved strain in the apex (i.e., apical sparing) is observed. A bull's eye plot is shown in the lower right panel

diphosphono-1,2-propanodicarboxylic acid (DPD), ${ }^{99 m}$ Tc-hydroxymethylene diphosphonate (HMDP), and technetium ${ }^{99 m}$ Tc-pyrophosphate (PYP), for the diagnosis of ATTR amyloidosis has recently increased (Fig. 6) [82, 83]. According to a study of 1217 patients suspected of having cardiac amyloidosis, the sensitivity and specificity of scintigraphy using these tracers for the diagnosis of ATTR amyloidosis were $>99$ and $86 \%$, respectively [83]. Of note, false positives almost exclusively resulted from uptake by $\mathrm{AL}$ amyloidosis patients, and combined findings of cardiac uptake equal to or greater than bone and the absence of serum and urinary monoclonal protein had a specificity and positive predictive value for ATTR amyloidosis of $100 \%$ [83]. Therefore, bone scintigraphy using ${ }^{99 \mathrm{~m}} \mathrm{Tc}-\mathrm{DPD},{ }^{99 \mathrm{~m}} \mathrm{Tc}-\mathrm{HMDP}$, or ${ }^{99 \mathrm{~m}} \mathrm{Tc}$ PYP is now used as a substitute for 

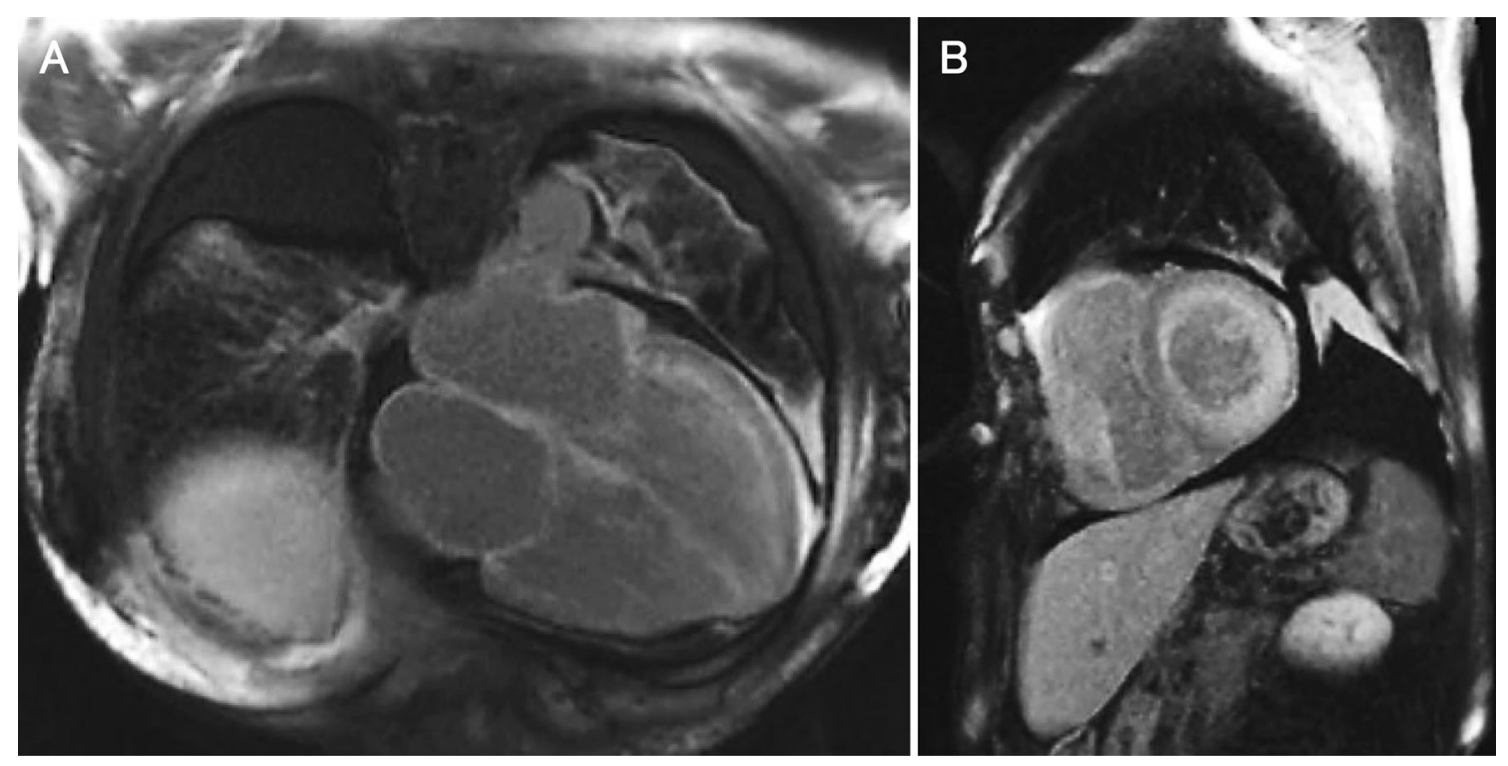

Fig. 3 Gadolinium-enhanced cardiac magnetic resonance imaging in a patient with ATTRwt amyloidosis. a Late gadolinium enhancement is observed along with the myocardial walls in an axial section. $\mathbf{b}$ The left ventricular

endomyocardial biopsy in the diagnosis of cardiomyopathy resulting from ATTR amyloidosis.

${ }^{123}$ I-Metaiodobenzylguanidine (MIBG) scintigraphy is an imaging technique to show cardiac sympathetic innervation [84]. MIBG has been used to evaluate heart failure in the cardiology field [85], whereas neurologists have also considered reduced myocardial MIBG uptake as one of the early signs of autonomic dysfunctions in neurological diseases, including ATTRv amyloidosis, even in the absence of heart failure $[25,50,86]$.

The results from studies using amyloid-specific tracers, such as ${ }^{11} \mathrm{C}$-Pittsburgh compound $\mathrm{B}$ (PiB) [87], ${ }^{18}$ F-florbetaben [88], and ${ }^{18} \mathrm{~F}$-florbetapir [89], for positron emission tomography (PET) have suggested the potential of these tracers for the detection of cardiac amyloidosis. Although the uptake of these tracers occurs not only in ATTR amyloidosis tissues but also in AL amyloidosis tissues [87-89], PET imaging can simultaneously visualize the distribution of amyloid deposits in other organs [90, 91].

Interestingly, a study of ${ }^{11} \mathrm{C}$-PiB PET revealed that cardiac ${ }^{11} \mathrm{C}-\mathrm{PiB}$ uptake is lower in patients with ATTRwt, late-onset ATTRVal30Met, and wall shows diffuse subendocardial or transmural late gadolinium enhancement without a coronary distribution pattern

ATTRnon-Val30Met amyloidosis than in early onset ATTRVal30Met amyloidosis patients [92]. According to previous histopathological studies, amyloid fibrils in early onset ATTRVal30Met patients from conventional endemic foci are generally long and thick and have a good affinity for Congo red accompanied by strong birefringence under polarized light (Fig. 7A-C) [51]. In contrast, amyloid fibrils in other types of ATTR amyloidosis (i.e., ATTRwt, late-onset ATTRVal30Met, and ATTRnon-Val30Met) are fine and have a weak affinity for Congo red accompanied by weak birefringence (Fig. 7D-F) $[32,51,52]$. Hence, these characteristics of amyloid fibrils may determine the affinity of ${ }^{11} \mathrm{C}$-PiB for amyloid deposits in ATTR amyloidosis patients.

\section{MANAGEMENT}

\section{General Considerations}

The management of ATTR amyloidosis requires a multidisciplinary approach. ATTRv amyloidosis patients who were initially referred to 


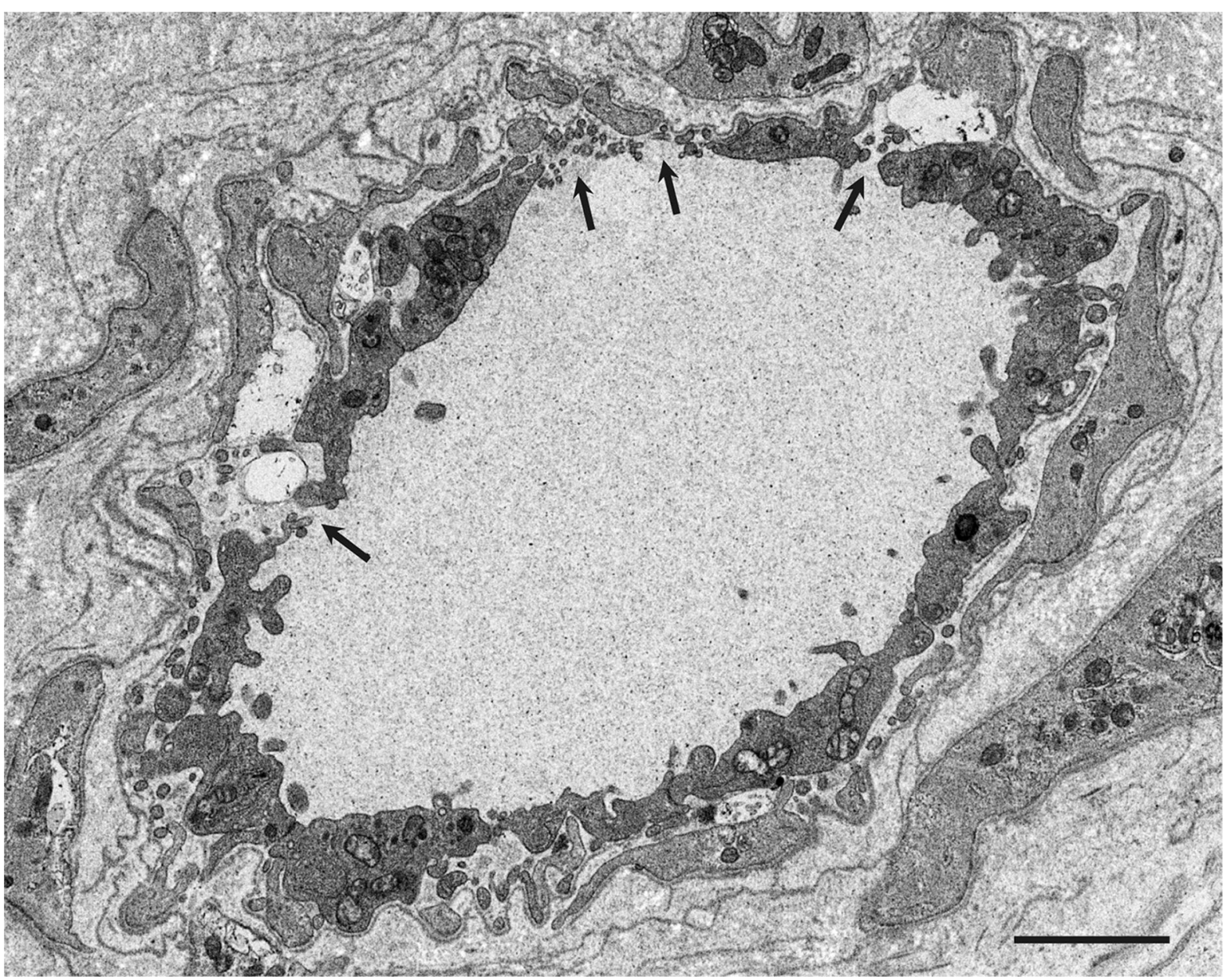

Fig. 4 Microangiopathy in a late-onset ATTRVal30Met amyloidosis patient from a nonendemic area of Japan. A cross section of a sural nerve biopsy specimen. Uranyl acetate and lead citrate-stained specimens. The continuity

neurologists usually complained of numbness or pain in the limbs [8]. Autonomic symptoms, such as orthostatic intolerance, diarrhea, constipation, and dysuria, are also frequent [23]. In addition to the disease-modifying therapies described later, treatments to ameliorate these symptoms are also important. Some of these patients may have severe neuropathic pain refractory to conventional medication, resulting in a significant disability [93]. An anesthesiology consultation may be worth considering in such cases [93]. A referral to urologists is also important, particularly in patients who already complain of dysuria. of the endothelial cells of an endoneurial microvessel is lost (arrows), indicating the disruption of the blood-nerve barrier at this site. Scale bar $2 \mu \mathrm{m}$

In contrast, ATTR amyloidosis patients initially referred to cardiologists usually have heart failure that may necessitate treatment, such as the administration of diuretics [9]. As conduction disorders and sudden death frequently occur in ATTR amyloidosis patients [8, 13], prophylactic pacemaker implantation should be considered accordingly $[1,9]$. Notably, both neurological and cardiac complications become evident as the disease progresses in patients with ATTRv amyloidosis [8]. Therefore, close communication between neurologists and cardiologists is needed, particularly for ATTRv amyloidosis patients. 


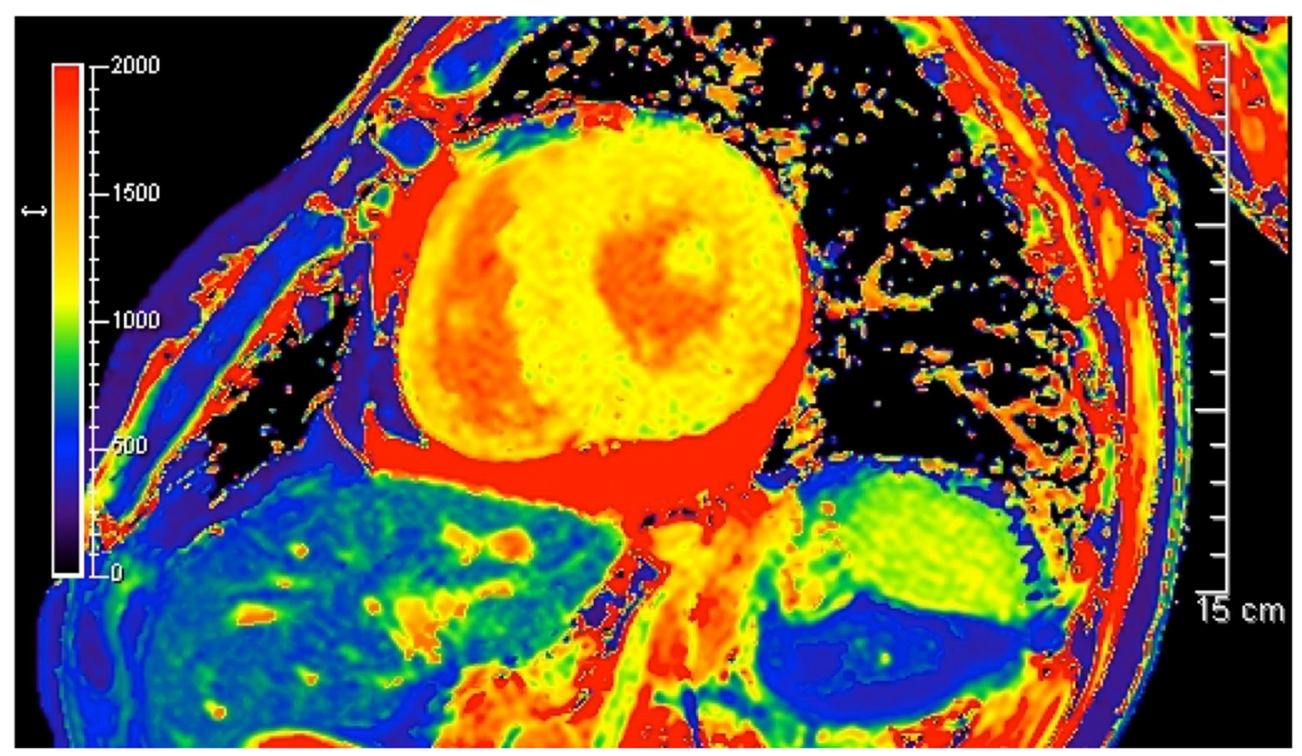

Fig. 5 Myocardial T1 mapping of magnetic resonance imaging in a late-onset ATTRVal30Met amyloidosis patient from a nonendemic area of Japan. Native myocardial T1 mapping indicates abnormally increased T1 relaxation time

An approach by ophthalmologists is also important for ATTRv amyloidosis patients because serious ophthalmological complications, such as vitreous opacity and glaucoma, may occur [94]. As variant TTR is produced independently from the retinal pigment epithelium in the eye, which is segregated from the systemic circulation by blood-ocular barriers, ocular amyloidosis progresses even though patients receive currently available diseasemodifying therapies [95].

\section{Disease-Modifying Therapies}

Liver transplantation Liver transplantation has been performed since 1990 in ATTRv amyloidosis patients to prevent the production of variant TTR from the liver [96]. Although longterm efficacy of liver transplantation has been confirmed with respect to survival, particularly in early onset ATTRVal30Met patients from conventional endemic foci [97], some of the patients exhibited a progression of neuropathy and cardiomyopathy resulting from wild-type TTR deposition even after liver transplantation [98-100]. According to the data obtained from the Familial Amyloidotic Polyneuropathy World Transplant Registry, an early age of onset, short disease duration, and Val30Met mutation are predictors for better survival [101].

As the production of TTR also occurs in organs other than the liver, such as the choroid plexus in the brain and retinal pigment epithelium in the eye [102], ocular and leptomeningeal amyloidosis become conspicuous long term after liver transplantation even though neuropathy and cardiomyopathy seem to be stable $[90,103]$.

TTR stabilizers Small molecules that stabilize the native quaternary structure of TTR tetramers by binding to thyroxin-binding sites have been considered to be effective for ATTR amyloidosis, as they prevent the dissociation of TTR tetramers into monomers, which is a crucial step for the subsequent process of protein misfolding and amyloid fibril formation [104, 105].

Tafamidis is an analog of thyroxine designed to bind to the thyroxin-binding site of TTR [106], and it can stabilize TTR tetramers and prevent their dissociation into monomers $[1,21]$. The first phase III trial enrolling 128 ATTRVal30Met amyloidosis patients with polyneuropathy in which patients were randomly assigned in a 1:1 ratio to receive $20 \mathrm{mg}$ of tafamidis (tafamidis meglumine) once daily or placebo for 18 months suggested efficacy in 


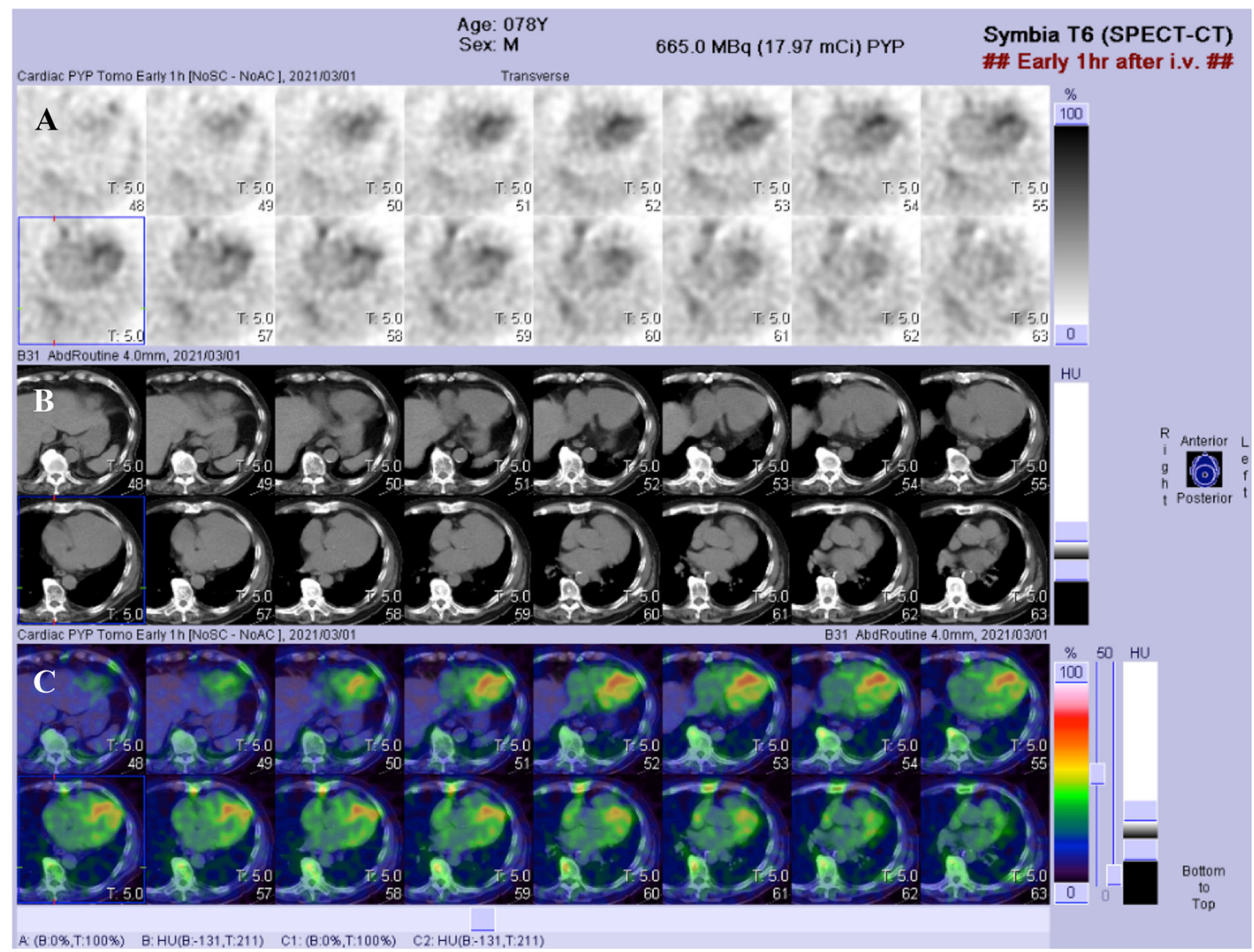

Fig. 6. ${ }^{99 \mathrm{~m}} \mathrm{Tc}$-Pyrophosphate cardiac scintigraphy images in a late-onset ATTRVal30Met amyloidosis patient from a nonendemic area of Japan. a Myocardial uptake of the ${ }^{99 \mathrm{~m}} \mathrm{Tc}$-pyrophosphate tracer is observed on axial planes of

terms of neuropathy and quality-of-life scores [107]. This drug was first approved for use in early ATTRv amyloidosis with polyneuropathy by the European Medicines Agency in 2011 and subsequently in other countries. A later prospective observation of ATTRv amyloidosis patients with polyneuropathy suggested a longterm efficacy of tafamidis for up to 6 years in terms of the slowing of neuropathy progression without any unexpected adverse events [108]. Another study using data from clinical trials where ATTRv amyloidosis patients with polyneuropathy received tafamidis for up to 8.5 years demonstrated a favorable survival rate compared with patients with a natural history of the disease $[8,109]$. single-photon emission computed tomography (SPECT). b Plain computed tomography (CT) images that correspond to a. c Reconstruction of SPECT images linked to plain CT images

The efficacy of tafamidis for cardiomyopathy resulting from ATTR amyloidosis was also evaluated by a phase III trial involving 441 patients who were randomly assigned to receive $80 \mathrm{mg}$ of tafamidis, $20 \mathrm{mg}$ of tafamidis, or placebo in a 2:1:2 ratio for 30 months [110]. This study included 335 ATTRwt amyloidosis patients and 106 ATTRv amyloidosis patients and demonstrated reduced all-cause mortality and cardiovascular hospitalization rates in patients receiving tafamidis. A subanalysis in this trial also demonstrated a reduced decline in qualityof-life scores [111]. The use of tafamidis for the treatment of cardiomyopathy resulting from ATTR amyloidosis was first approved by the Pharmaceuticals and Medical Devices Agency of 

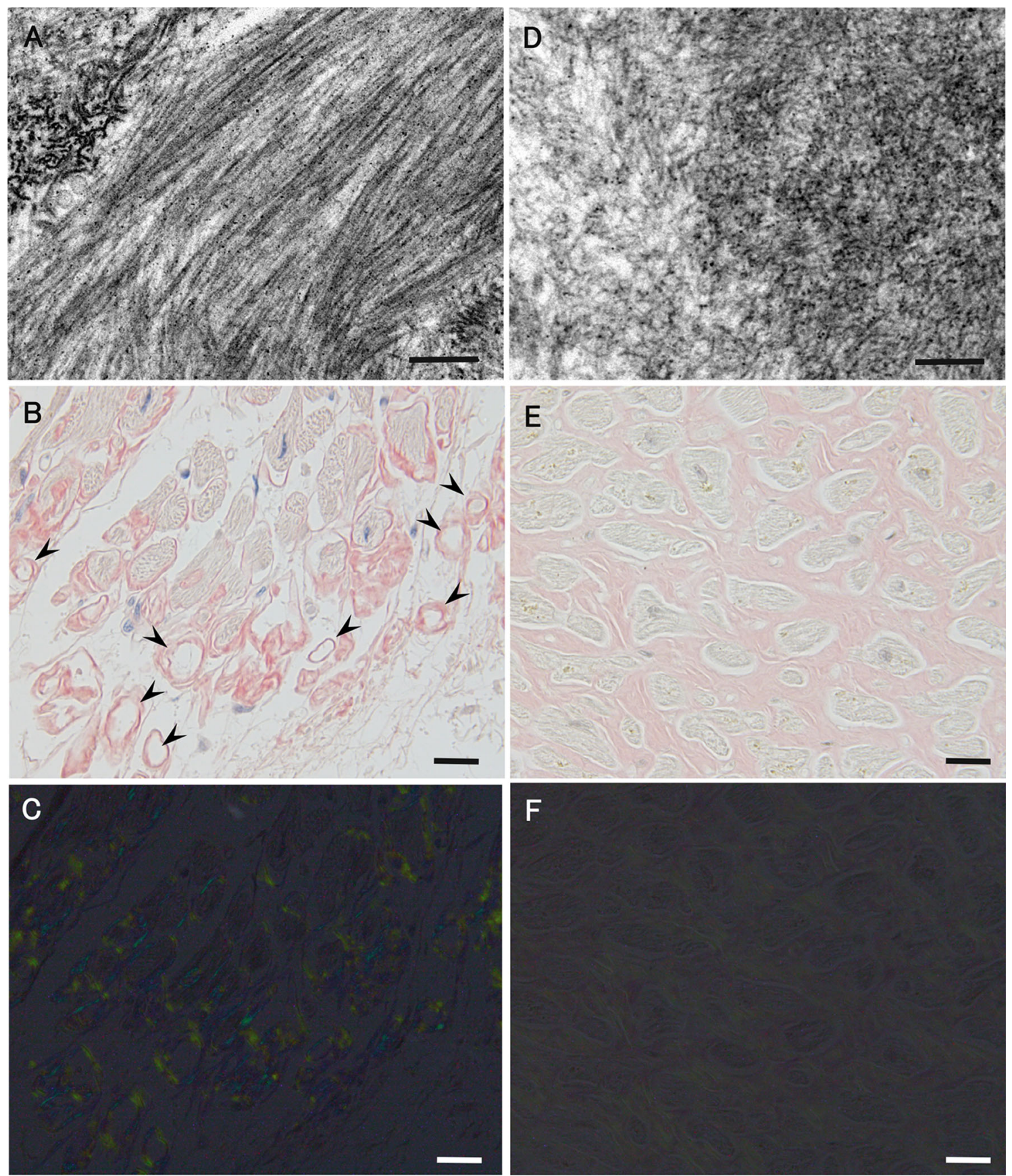

F

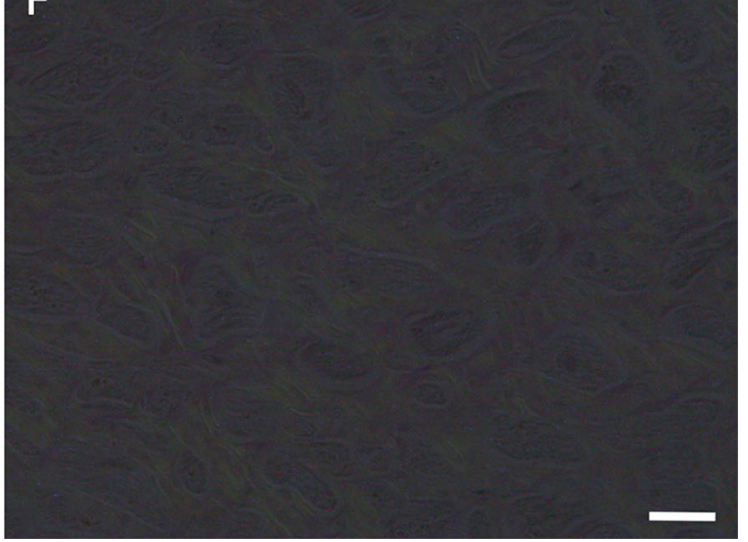


4Fig. 7 Differential characteristics of amyloid deposits between early onset ATTRVal30Met amyloidosis patients from conventional endemic foci $(\mathbf{a}-\mathbf{c})$ and late-onset ATTRVal30Met amyloidosis patients from nonendemic areas $(\mathbf{d}-\mathbf{f})$. Biopsy specimens of the sural nerve $(\mathbf{a}, \mathbf{d})$ and autopsy specimens of the heart (b, c, e, f). Uranyl acetate and lead citrate-stained specimens (a, d). Alkaline Congo red-stained specimens (b, c, e, f). On electron microscopy, amyloid fibrils tend to be long and thick in early onset patients from endemic foci (a). On light microscopy, amyloid deposits tend to be highly congophilic (b) and exhibit a strong apple-green birefringence under polarized light (c) in early onset patients from endemic foci. The atrophy and degeneration of myocardial cells result in the formation of amyloid rings (arrowhead). In late-onset patients from nonendemic areas, amyloid fibrils are generally short and thin on electron microscopy (d). On light microscopy, amyloid deposits are generally weakly congophilic (e) and exhibit a faint apple-green birefringence $(\mathbf{f})$ in late-onset patients from nonendemic areas. Compared with (b), the atrophy of myocardial cells is not conspicuous despite massive amyloid deposition in (e). Scale bars $0.2 \mu \mathrm{m}$ (a and d) and $20 \mu \mathrm{m}(\mathbf{b}, \mathbf{C}$, e, and $\mathbf{f})$

Japan in February 2019 and subsequently approved by the United States Food and Drug Administration and the European Medicines Agency.

Diflunisal is another TTR stabilizer that has been used as a nonsteroidal anti-inflammatory drug [105]. A study involving 130 ATTRv amyloidosis patients who were randomly assigned in a $1: 1$ ratio to receive $250 \mathrm{mg}$ of diflunisal twice daily or placebo for 2 years suggested that this drug can also delay the progression of neuropathy [112]. Expected adverse events resulting from the use of nonsteroidal anti-inflammatory drugs, such as gastrointestinal and renal disorders, were not different between diflunisal and placebo groups in this study.

Gene silencing agents As ATTR amyloidosis is a gain-of-toxic-function protein misfolding disease, the elimination of causative proteins by gene silencing agents has been considered to be another therapeutic strategy for this disease [113].

Patisiran is an RNA interference therapeutic composed of an siRNA formulated as a lipid nanoparticle designed to be delivered to the liver to reduce TTR production [1]. In a phase III trial, 225 ATTRv amyloidosis patients with polyneuropathy were randomly assigned in a $2: 1$ ratio to receive intravenous patisiran $(0.3 \mathrm{mg} / \mathrm{kg}$ of body weight) or placebo once every 3 weeks [114]. In addition to better primary outcome measures represented by neuropathy and quality-of-life scores, exploratory cardiac measures were also better in patients who received patisiran than in those who received placebo. A subgroup analysis of prespecified patients with cardiomyopathy showed that patisiran decreased left ventricular wall thickness, global longitudinal strain, and NTproBNP compared with placebo $[115,116]$. Subsequent reports of open-label extension studies demonstrated that patisiran maintained efficacy with an acceptable safety profile in ATTRv amyloidosis patients with polyneuropathy for up to 30 months $[117,118]$.

Inotersen is a second-generation ASO designed to prevent the production of TTR [113]. A phase III trial involving 172 ATTRv amyloidosis patients in which patients were randomly assigned to receive weekly subcutaneous injections of inotersen $(300 \mathrm{mg}$ ) or placebo in a 2:1 ratio for 15 months demonstrated significantly better primary endpoints represented by neuropathy impairment and qualityof-life scores [119]. A subsequent open-label extension study reported 2 years later reconfirmed the results of this study [120]. Additionally, another open-label study assessing ATTR amyloidosis patients with cardiomyopathy suggested the efficacy of inotersen even for cardiomyopathy [121]. Because glomerulonephritis and thrombocytopenia were reported as severe adverse events, close monitoring of platelet count and renal function is required in patients receiving inotersen. To improve the safety profile, a ligand-conjugated ASO of a nucleotide sequence identical to that of inotersen designed to facilitate receptor-mediated uptake by hepatocytes was also designed [122]. Currently, it is under investigation in phase III trials in ATTRv amyloidosis patients with polyneuropathy and ATTR patients with cardiomyopathy [122, 123]. 


\section{SUMMARY AND CONCLUSIONS}

ATTR amyloidosis, mainly including ATTRv amyloidosis and ATTRwt amyloidosis, is a systemic disease that necessitates multidisciplinary approaches for diagnosis and treatment. Until recently, ATTRv amyloidosis has been considered a disease in the field of neurology because neuropathic symptoms predominated in patients described in early reports [3], whereas advances in diagnostic techniques and increased recognition of this disease revealed the presence of patients with cardiomyopathy as a predominant feature [7-9, 25]. In contrast, ATTRwt amyloidosis has been considered a disease in the field of cardiology [10]. However, recent studies have suggested that some patients present tenosynovial tissue complications, particularly carpal tunnel syndrome, as an initial manifestation of amyloidosis [13, 14], suggesting the necessity of an awareness of this disease among neurologists and orthopedists.

Although a histopathological confirmation of amyloid deposits has traditionally been considered mandatory for the diagnosis of ATTR amyloidosis [1], the development of noninvasive imaging techniques in the field of cardiology, such as echocardiography, MRI, and nuclear imaging, enabled nonbiopsy diagnosis of this disease. In particular, bone scintigraphy using ${ }^{99 \mathrm{~m}} \mathrm{Tc}-\mathrm{DPD},{ }^{99 \mathrm{~m}} \mathrm{Tc}-\mathrm{HMDP}$, or ${ }^{99 \mathrm{~m}} \mathrm{Tc}-\mathrm{PYP}$ is now used as a substitute for endomyocardial biopsy for the diagnosis of cardiomyopathy resulting from ATTR amyloidosis [83].

The mechanisms underlying characteristic cardiac imaging findings have been deciphered by histopathological studies. For example, the leakage of gadolinium on MRI, called LGE, seems to be associated with microangiopathy that enhances the leakage of serum components from the lumina of vessels [72]. Myocardial T2 mapping used to demonstrate myocardial edema supports this view [73]. Cardiac ${ }^{11} \mathrm{C}-\mathrm{PiB}$ uptake is lower in patients with ATTRwt, lateonset Val30Met ATTRv, and ATTRnon-Val30Met amyloidosis than in early onset ATTRVal30Met amyloidosis patients [92], corresponding to the differences in the characteristics of amyloid fibrils in these patients [32, 51, 52].

Novel disease-modifying therapies for ATTR amyloidosis, such as TTR stabilizers, siRNA, and ASO, were initially approved for ATTRv amyloidosis patients with polyneuropathy $[107,112,114,119]$. However, the indications for these novel disease-modifying therapies gradually widened to include ATTRv and ATTRwt amyloidosis patients with cardiomyopathy [110]. Therefore, the necessity for close cooperation of multiple departments is increasing to facilitate earlier diagnosis and better management to maintain patients' quality of life. Currently, we have little knowledge on whether all patients will positively respond to all disease-modifying therapies or whether there will be some who respond only to a specific therapy or do not respond at all [124]. A strategy for monitoring patients that enables the choice of an appropriate treatment for individual patients should also be established from multiple perspectives.

Since the pandemic of coronavirus disease 2019 (COVID-19), which is caused by severe acute respiratory syndrome coronavirus 2 (SARS-CoV-2) infection, occurred, the minimization of hospital visits and telemedicine have become increasingly important $[125,126]$. As older age and cardiovascular disease are major factors associated with increased disease severity and mortality of COVID-19 [127, 128], many ATTR amyloidosis patients are at increased risk of disease aggravation when they are infected with SARS-CoV-2. ATTRv amyloidosis patients who have undergone liver transplantation and receive immunosuppressive agents may also have a risk of higher mortality, although the association between liver transplantation and COVID-19 is still under debate [129-131]. From this viewpoint, close interspecialty communication to determine the optimal interval of evaluation is needed for the management of patients with ATTR amyloidosis. 


\section{ACKNOWLEDGEMENTS}

Funding. This work was supported by grants from the Ministry of Health, Labor and Welfare of Japan (Research on rare and intractable diseases, H29-022).

Authorship. All named authors meet the International Committee of Medical Journal Editors (ICMJE) criteria for authorship for this article, take responsibility for the integrity of the work as a whole, and have given their approval for this version to be published.

Disclosures. Haruki Koike and Masahisa Katsuno report consulting fees and travel fees from Pfizer and Alnylam. Takahiro Okumura reports lecture fees from Pfizer and research grants from Alnylam and Alexion Pharma. Toyoaki Murohara has nothing to disclose.

Compliance with Ethics Guidelines. This article is based on previously conducted studies and does not contain any studies with human participants or animals performed by any of the authors.

Data Availability. Data sharing is not applicable to this article as no datasets were generated or analyzed during the current study.

Open Access. This article is licensed under a Creative Commons Attribution-NonCommercial 4.0 International License, which permits any non-commercial use, sharing, adaptation, distribution and reproduction in any medium or format, as long as you give appropriate credit to the original author(s) and the source, provide a link to the Creative Commons licence, and indicate if changes were made. The images or other third party material in this article are included in the article's Creative Commons licence, unless indicated otherwise in a credit line to the material. If material is not included in the article's Creative Commons licence and your intended use is not permitted by statutory regulation or exceeds the permitted use, you will need to obtain permission directly from the copyright holder. To view a copy of this licence, visit http:// creativecommons.org/licenses/by-nc/4.0/.

\section{REFERENCES}

1. Adams D, Koike H, Slama M, Coelho T. Hereditary transthyretin amyloidosis: a model of medical progress for a fatal disease. Nat Rev Neurol. 2019;15(7): 387-404.

2. Benson MD, Buxbaum JN, Eisenberg DS, Merlini G, Saraiva MJM, Sekijima Y, Sipe JD, Westermark P. Amyloid nomenclature 2020: update and recommendations by the International Society of Amyloidosis (ISA) nomenclature committee. Amyloid. 2020;27(4):217-22.

3. Koike H, Katsuno M. Transthyretin amyloidosis: update on the clinical spectrum, pathogenesis, and disease-modifying therapies. Neurol Ther. 2020;9(2):317-33.

4. Andrade C. A peculiar form of peripheral neuropathy; familiar atypical generalized amyloidosis with special involvement of the peripheral nerves. Brain. 1952;75(3):408-27.

5. Araki S, Mawatari S, Ohta M, Nakajima A, Kuroiwa Y. Polyneuritic amyloidosis in a Japanese family. Arch Neurol. 1968;18(6):593-602.

6. Andersson R. Familial amyloidosis with polyneuropathy. A clinical study based on patients living in Northern Sweden. Acta Med Scand Suppl. 1976;590: $1-64$.

7. Rapezzi C, Quarta CC, Riva L, Longhi S, Gallelli I, Lorenzini M, Ciliberti P, Biagini E, Salvi F, Branzi A. Transthyretin-related amyloidoses and the heart: a clinical overview. Nat Rev Cardiol. 2010;7(7): 398-408.

8. Koike H, Tanaka F, Hashimoto R, Tomita M, Kawagashira Y, Iijima M, Fujitake J, Kawanami T, Kato T, Yamamoto M, Sobue G. Natural history of transthyretin Val30Met familial amyloid polyneuropathy: analysis of late-onset cases from non-endemic areas. J Neurol Neurosurg Psychiatry. 2012;83(2): 152-8.

9. Sekijima Y, Ueda M, Koike $H$, Misawa S, Ishii T, Ando Y. Diagnosis and management of transthyretin familial amyloid polyneuropathy in Japan: redflag symptom clusters and treatment algorithm. Orphanet J Rare Dis. 2018;13(1):6.

10. Cornwell GG III, Murdoch WL, Kyle RA, Westermark P, Pitkänen P. Frequency and distribution of 
senile cardiovascular amyloid. A clinicopathologic correlation. Am J Med. 1983;75(4):618-23.

11. Martinez-Naharro A, Baksi AJ, Hawkins PN, Fontana M. Diagnostic imaging of cardiac amyloidosis. Nat Rev Cardiol. 2020;17(7):413-26.

12. Kittleson MM, Maurer MS, Ambardekar AV, Bullock-Palmer RP, Chang PP, Eisen HJ, Nair AP, NativiNicolau J, Ruberg FL, American Heart Association Heart Failure and Transplantation Committee of the Council on Clinical Cardiology. Cardiac amyloidosis: evolving diagnosis and management: a scientific statement from the American Heart Association. Circulation. 2020;142(1):e7-22.

13. Sekijima Y, Yazaki M, Ueda M, Koike H, Yamada M, Ando Y. First nationwide survey on systemic wildtype ATTR amyloidosis in Japan. Amyloid. 2018;25(1):8-10.

14. Cappelli F, Zampieri M, Fumagalli C, Nardi G, Del Monaco G, Matucci Cerinic M, Allinovi M, Taborchi G, Martone R, Gabriele M, Ungar A, Moggi Pignone A, Marchionni N, Di Mario C, Olivotto I, Perfetto F. Tenosynovial complications identify TTR cardiac amyloidosis among patients with hypertrophic cardiomyopathy phenotype. J Intern Med. 2021;289(6):831-9.

15. Vianello PF, La Malfa G, Tini G, Mazzola V, Miceli A, Santolini E, Briano S, Porto I, Canepa M. Prevalence of transthyretin amyloid cardiomyopathy in male patients who underwent bilateral carpal tunnel surgery: the ACTUAL study. Int J Cardiol. 2021;15(329):144-7.

16. Westermark P, Westermark GT, Suhr OB, Berg S. Transthyretin-derived amyloidosis: probably a common cause of lumbar spinal stenosis. Ups J Med Sci. 2014;119(3):223-8.

17. Yanagisawa A, Ueda M, Sueyoshi T, Okada T, Fujimoto T, Ogi Y, Kitagawa K, Tasaki M, Misumi Y, Oshima T, Jono H, Obayashi K, Hirakawa K, Uchida $\mathrm{H}$, Westermark P, Ando Y, Mizuta H. Amyloid deposits derived from transthyretin in the ligamentum flavum as related to lumbar spinal canal stenosis. Mod Pathol. 2015;28(2):201-7.

18. Okumura T, Murohara T. Advantages and emerging problems of novel treatments for transthyretin cardiac amyloidosis. Circ J. 2019;84(1):9-10.

19. Garcia-Pavia P, Rapezzi C, Adler Y, Arad M, Basso C, Brucato A, Burazor I, Caforio ALP, Damy T, Eriksson U, Fontana M, Gillmore JD, Gonzalez-Lopez E, Grogan M, Heymans S, Imazio M, Kindermann I, Kristen AV, Maurer MS, Merlini G, Pantazis A, Pankuweit S, Rigopoulos AG, Linhart A. Diagnosis and treatment of cardiac amyloidosis: a position statement of the ESC Working Group on
Myocardial and Pericardial Diseases. Eur Heart J. 2021;42(16):1554-68.

20. Kelly JW. Amyloid fibril formation and protein misassembly: a structural quest for insights into amyloid and prion diseases. Structure. 1997;5(5): 595-600.

21. Koike H, Katsuno M. Ultrastructure in transthyretin amyloidosis: from pathophysiology to therapeutic insights. Biomedicines. 2019;7(1):11.

22. Sekijima $Y$, Wiseman RL, Matteson J, Hammarström P, Miller SR, Sawkar AR, Balch WE, Kelly JW. The biological and chemical basis for tissue-selective amyloid disease. Cell. 2005;121(1):73-85.

23. Koike H, Misu K, Ikeda S, Ando Y, Nakazato M, Ando E, Yamamoto M, Hattori N, Sobue G, Study Group for Hereditary Neuropathy in Japan. Type I (transthyretin Met30) familial amyloid polyneuropathy in Japan: early- vs late-onset form. Arch Neurol. 2002;59(11):1771-6.

24. Koike H, Hashimoto R, Tomita M, Kawagashira Y, Iijima M, Tanaka F, Sobue G. Diagnosis of sporadic transthyretin Val30Met familial amyloid polyneuropathy: a practical analysis. Amyloid. 2011;18(2): 53-62.

25. Koike H, Nakamura T, Nishi R, Ikeda S, Kawagashira Y, Iijima M, Katsuno M, Sobue G. Widespread cardiac and vasomotor autonomic dysfunction in nonVal30Met hereditary transthyretin amyloidosis. Intern Med. 2018;57(23):3365-70.

26. Buxbaum JN, Ruberg FL. Transthyretin V122I $(\mathrm{pV} 142 \mathrm{I})^{*}$ cardiac amyloidosis: an age-dependent autosomal dominant cardiomyopathy too common to be overlooked as a cause of significant heart disease in elderly African Americans. Genet Med. 2017;19(7):733-42.

27. Damrauer SM, Chaudhary K, Cho JH, Liang LW, Argulian E, Chan L, Dobbyn A, Guerraty MA, Judy R, Kay J, Kember RL, Levin MG, Saha A, Van Vleck T, Verma SS, Weaver J, Abul-Husn NS, Baras A, Chirinos JA, Drachman B, Kenny EE, Loos RJF, Narula J, Overton J, Reid J, Ritchie M, Sirugo G, Nadkarni G, Rader DJ, Do R. Association of the V122I hereditary transthyretin amyloidosis genetic variant with heart failure among individuals of African or Hispanic/Latino ancestry. JAMA. 2019;322(22):2191-202.

28. Gentile L, Di Bella G, Minutoli F, Cucinotta F, Obici L, Mussinelli R, Arimatea I, Russo M, Toscano A, Vita G, Mazzeo A. Description of a large cohort of Caucasian patients with V122I ATTRv amyloidosis: Neurological and cardiological features. J Peripher Nerv Syst. 2020;25(3):273-8. 
29. Schneider F, Hammarström P, Kelly JW. Transthyretin slowly exchanges subunits under physiological conditions: a convenient chromatographic method to study subunit exchange in oligomeric proteins. Protein Sci. 2001;10(8):1606-13.

30. Suhr OB, Lundgren E, Westermark P. One mutation, two distinct disease variants: unravelling the impact of transthyretin amyloid fibril composition. J Intern Med. 2017;281(4):337-47.

31. Pras M, Franklin EC, Prelli F, Frangione B. A variant of prealbumin from amyloid fibrils in familial polyneuropathy of Jewish origin. J Exp Med. 1981;154(3):989-93.

32. Bergström J, Gustavsson A, Hellman U, Sletten K, Murphy CL, Weiss DT, Solomon A, Olofsson BO, Westermark P. Amyloid deposits in transthyretinderived amyloidosis: cleaved transthyretin is associated with distinct amyloid morphology. J Pathol. 2005;206(2):224-32.

33. Jacobson DR, Pastore RD, Yaghoubian R, Kane I, Gallo G, Buck FS, Buxbaum JN. Variant-sequence transthyretin (isoleucine 122) in late-onset cardiac amyloidosis in black Americans. N Engl J Med. 1997;336(7):466-73.

34. Ueda M, Horibata Y, Shono M, Misumi Y, Oshima T, Su Y, Tasaki M, Shinriki S, Kawahara S, Jono H, Obayashi K, Ogawa H, Ando Y. Clinicopathological features of senile systemic amyloidosis: an ante- and post-mortem study. Mod Pathol. 2011;24(12): 1533-44.

35. González-López E, Gallego-Delgado M, Guzzo-Merello G, de Haro-Del Moral FJ, Cobo-Marcos M, Robles C, Bornstein B, Salas C, Lara-Pezzi E, AlonsoPulpon L, Garcia-Pavia P. Wild-type transthyretin amyloidosis as a cause of heart failure with preserved ejection fraction. Eur Heart J. 2015;36(38): 2585-94.

36. Griffin JM, Maurer MS. Transthyretin cardiac amyloidosis: a treatable form of heart failure with a preserved ejection fraction. Trends Cardiovasc Med. 2021;31(1):59-66.

37. Stein K, Störkel S, Linke RP, Goebel HH. Chemical heterogeneity of amyloid in the carpal tunnel syndrome. Virchows Arch A Pathol Anat Histopathol. 1987;412(1):37-45.

38. Kyle RA, Gertz MA, Linke RP. Amyloid localized to tenosynovium at carpal tunnel release. Immunohistochemical identification of amyloid type. Am J Clin Pathol. 1992;97(2):250-3.

39. Sekijima Y, Uchiyama S, Tojo K, Sano K, Shimizu Y, Imaeda T, Hoshii Y, Kato H, Ikeda S. High prevalence of wild-type transthyretin deposition in patients with idiopathic carpal tunnel syndrome: a common cause of carpal tunnel syndrome in the elderly. Hum Pathol. 2011;42(11):1785-91.

40. Sueyoshi T, Ueda M, Jono H, Irie H, Sei A, Ide J, Ando Y, Mizuta H. Wild-type transthyretin-derived amyloidosis in various ligaments and tendons. Hum Pathol. 2011;42(9):1259-64.

41. Eldhagen P, Berg S, Lund LH, Sörensson P, Suhr OB, Westermark P. Transthyretin amyloid deposits in lumbar spinal stenosis and assessment of signs of systemic amyloidosis. J Intern Med. 2021;289(6): 895-905.

42. Koike H, Misu K, Sugiura M, Iijima M, Mori K, Yamamoto M, Hattori N, Mukai E, Ando Y, Ikeda S, Sobue G. Pathology of early- vs late-onset TTR Met30 familial amyloid polyneuropathy. Neurology. 2004;63(1):129-38.

43. Koike H, Kawagashira Y, Iijima M, Yamamoto $M$, Hattori N, Tanaka F, Hirayama M, Ando Y, Ikeda S, Sobue G. Electrophysiological features of late-onset transthyretin Met30 familial amyloid polyneuropathy unrelated to endemic foci. J Neurol. 2008;255(10):1526-33.

44. Koike H, Morozumi S, Kawagashira Y, Iijima M, Yamamoto M, Hattori N, Tanaka F, Nakamura T, Hirayama M, Ando Y, Ikeda S, Sobue G. The significance of carpal tunnel syndrome in transthyretin Val30Met familial amyloid polyneuropathy. Amyloid. 2009;16(3):142-8.

45. Ebenezer GJ, Liu Y, Judge DP, Cunningham K, Truelove S, Carter ND, Sebastian B, Byrnes K, Polydefkis M. Cutaneous nerve biomarkers in transthyretin familial amyloid polyneuropathy. Ann Neurol. 2017;82(1):44-56.

46. Chao CC, Hsueh HW, Kan HW, Liao CH, Jiang HH, Chiang H, Lin WM, Yeh TY, Lin YH, Cheng YY, Hsieh ST. Skin nerve pathology: biomarkers of premanifest and manifest amyloid neuropathy. Ann Neurol. 2019;85(4):560-73.

47. Chiang MC, Yeh TY, Sung JY, Hsueh HW, Kao YH, Hsueh SJ, Chang KC, Feng FP, Lin YH, Chao CC, Hsieh ST. Early changes of nerve integrity in preclinical carriers of hereditary transthyretin Ala117Ser amyloidosis with polyneuropathy. Eur J Neurol. 2021;28(3):982-91.

48. Marume K, Takashio S, Nishi M, Hirakawa $K$, Yamamoto M, Hanatani S, Oda S, Utsunomiya D, Shiraishi S, Ueda M, Yamashita T, Sakamoto K, Yamamoto E, Kaikita K, Izumiya Y, Yamashita Y, Ando Y, Tsujita K. Combination of commonly examined parameters is a useful predictor of positive ${ }^{99 \mathrm{~m}}$ Tc-labeled pyrophosphate scintigraphy findings in elderly patients with suspected 
transthyretin cardiac amyloidosis. Circ J. 2019;83(8):1698-708.

49. Ikeda S. Cardiac amyloidosis: heterogenous pathogenic backgrounds. Intern Med. 2004;43(12): 1107-14.

50. Koike H, Nakamura T, Hashizume A, Nishi R, Ikeda S, Kawagashira Y, Iijima M, Katsuno M, Sobue G. Cardiac and peripheral vasomotor autonomic functions in late-onset transthyretin Val30Met familial amyloid polyneuropathy. J Neurol. 2017;264(11):2293-302.

51. Koike H, Ando Y, Ueda M, Kawagashira Y, Iijima M, Fujitake J, Hayashi M, Yamamoto M, Mukai E, Nakamura T, Katsuno M, Hattori N, Sobue G. Distinct characteristics of amyloid deposits in earlyand late-onset transthyretin Val30Met familial amyloid polyneuropathy. J Neurol Sci. 2009;287(1-2):178-84.

52. Koike H, Nishi R, Ikeda S, Kawagashira Y, Iijima M, Sakurai T, Shimohata T, Katsuno M, Sobue G. The morphology of amyloid fibrils and their impact on tissue damage in hereditary transthyretin amyloidosis: an ultrastructural study. J Neurol Sci. 2018;15(394):99-106.

53. Reixach N, Deechongkit S, Jiang X, Kelly JW, Buxbaum JN. Tissue damage in the amyloidoses: transthyretin monomers and nonnative oligomers are the major cytotoxic species in tissue culture. Proc Natl Acad Sci USA. 2004;101(9):2817-22.

54. Ueda M, Sekijima Y, Koike H, Yamashita T, Yoshinaga $\mathrm{T}$, Ishii $\mathrm{T}$, Ando $\mathrm{Y}$. Monitoring of asymptomatic family members at risk of hereditary transthyretin amyloidosis for early intervention with disease-modifying therapies. J Neurol Sci. 2020;15(414):116813.

55. Koike H, Mouri N, Fukami Y, Iijima M, Matsuo K, Yagi N, Saito A, Nakamura H, Takahashi K, Nakae Y, Okada Y, Tanaka F, Sobue G, Katsuno M. Two distinct mechanisms of neuropathy in immunoglobulin light chain (AL) amyloidosis. J Neurol Sci. 2021;2(421):117305.

56. Ueda M, Misumi Y, Mizuguchi M, Nakamura M, Yamashita T, Sekijima Y, Ota K, Shinriki S, Jono H, Ikeda S, Suhr OB, Ando Y. SELDI-TOF mass spectrometry evaluation of variant transthyretins for diagnosis and pathogenesis of familial amyloidotic polyneuropathy. Clin Chem. 2009;55(6):1223-7.

57. Klein CJ, Vrana JA, Theis JD, Dyck PJ, Dyck PJ, Spinner RJ, Mauermann ML, Bergen HR III, Zeldenrust SR, Dogan A. Mass spectrometric-based proteomic analysis of amyloid neuropathy type in nerve tissue. Arch Neurol. 2011;68(2):195-9.
58. Benson MD, Dasgupta NR, Rao R. Diagnosis and screening of patients with hereditary transthyretin amyloidosis (hATTR): current strategies and guidelines. Ther Clin Risk Manag. 2020;14(16):749-58.

59. Granstam SO, Rosengren S, Vedin O, Kero T, Sörensen J, Carlson K, Flachskampf FA, Wikström G. Evaluation of patients with cardiac amyloidosis using echocardiography, ECG and right heart catheterization. Amyloid. 2013;20(1):27-33.

60. Koyama J, Ray-Sequin PA, Falk RH. Longitudinal myocardial function assessed by tissue velocity, strain, and strain rate tissue Doppler echocardiography in patients with AL (primary) cardiac amyloidosis. Circulation. 2003;107(19):2446-52.

61. Bellavia D, Abraham TP, Pellikka PA, Al-Zahrani GB, Dispenzieri A, Oh JK, Bailey KR, Wood CM, Novo S, Miyazaki C, Miller FA Jr. Detection of left ventricular systolic dysfunction in cardiac amyloidosis with strain rate echocardiography. J Am Soc Echocardiogr. 2007;20(10):1194-202.

62. Ogiwara F, Koyama J, Ikeda S, Kinoshita O, Falk RH. Comparison of the strain Doppler echocardiographic features of familial amyloid polyneuropathy (FAP) and light-chain amyloidosis. Am J Cardiol. 2005;95(4):538-40.

63. Phelan D, Thavendiranathan P, Popovic Z, Collier P, Griffin B, Thomas JD, Marwick TH. Application of a parametric display of two-dimensional speckletracking longitudinal strain to improve the etiologic diagnosis of mild to moderate left ventricular hypertrophy. J Am Soc Echocardiogr. 2014;27(8): 888-95.

64. Quarta CC, Solomon SD, Uraizee I, Kruger J, Longhi S, Ferlito M, Gagliardi C, Milandri A, Rapezzi C, Quarta CC, Riva L, Longhi S, Gallelli I, Lorenzini M, Ciliberti P, Biagini E, Salvi F, Branzi A. Transthyretin-related amyloidoses and the heart: a clinical overview. Nat Rev Cardiol. 2010;7(7):398-408.

65. Podnar S, Sarafov S, Tournev I, Omejec G, Zidar J. Peripheral nerve ultrasonography in patients with transthyretin amyloidosis. Clin Neurophysiol. 2017;128(4):505-11.

66. Salvalaggio A, Coraci D, Cacciavillani M, Padua L, Briani C. Nerve ultrasonography features in hereditary transthyretin amyloidosis with V30M mutation and polyneuropathy. Neurol Sci. (In press).

67. Misumi Y, Ueda M, Yamashita T, Masuda T, Kinoshita Y, Tasaki M, Nagase T, Ando Y. Novel screening for transthyretin amyloidosis by using fat ultrasonography. Ann Neurol. 2017;81(4):604-8.

68. Maceira AM, Prasad SK, Hawkins PN, Roughton M, Pennell DJ. Cardiovascular magnetic resonance and 
prognosis in cardiac amyloidosis. J Cardiovasc Magn Reson. 2008;10(1):54.

69. Martinez-Naharro A, Treibel TA, Abdel-Gadir A, Bulluck H, Zumbo G, Knight DS, Kotecha T, Francis R, Hutt DF, Rezk T, Rosmini S, Quarta CC, Whelan CJ, Kellman P, Gillmore JD, Moon JC, Hawkins PN, Fontana M. Magnetic resonance in transthyretin cardiac amyloidosis. J Am Coll Cardiol. 2017;70(4): 466-77.

70. Fontana M, Pica S, Reant P, Abdel-Gadir A, Treibel TA, Banypersad SM, Maestrini V, Barcella W, Rosmini S, Bulluck H, Sayed RH, Patel K, Mamhood S, Bucciarelli-Ducci C, Whelan CJ, Herrey AS, Lachmann $\mathrm{HJ}$, Wechalekar $\mathrm{AD}$, Manisty $\mathrm{CH}$, Schelbert EB, Kellman P, Gillmore JD, Hawkins PN, Moon JC. Prognostic value of late gadolinium enhancement cardiovascular magnetic resonance in cardiac amyloidosis. Circulation. 2015;132(16):1570-9.

71. Dungu JN, Valencia O, Pinney JH, Gibbs SD, Rowczenio D, Gilbertson JA, Lachmann HJ, Wechalekar A, Gillmore JD, Whelan CJ, Hawkins PN, Anderson LJ. CMR-based differentiation of AL and ATTR cardiac amyloidosis. JACC Cardiovasc Imaging. 2014;7(2):133-42.

72. Koike H, Ikeda S, Takahashi M, Kawagashira Y, Iijima M, Misumi Y, Ando Y, Ikeda SI, Katsuno M, Sobue G. Schwann cell and endothelial cell damage in transthyretin familial amyloid polyneuropathy. Neurology. 2016;87(21):2220-9.

73. Kotecha T, Martinez-Naharro A, Treibel TA, Francis R, Nordin S, Abdel-Gadir A, Knight DS, Zumbo G, Rosmini S, Maestrini V, Bulluck H, Rakhit RD, Wechalekar AD, Gilbertson J, Sheppard MN, Kellman P, Gillmore JD, Moon JC, Hawkins PN, Fontana M. Myocardial edema and prognosis in amyloidosis. J Am Coll Cardiol. 2018;71(25): 2919-31.

74. Fontana M, Banypersad SM, Treibel TA, Maestrini V, Sado DM, White SK, Pica S, Castelletti S, Piechnik SK, Robson MD, Gilbertson JA, Rowczenio D, Hutt DF, Lachmann HJ, Wechalekar AD, Whelan CJ, Gillmore JD, Hawkins PN, Moon JC. Native T1 mapping in transthyretin amyloidosis. JACC Cardiovasc Imaging. 2014;7(2):157-65.

75. Fontana M, Banypersad SM, Treibel TA, Abdel-Gadir A, Maestrini V, Lane T, Gilbertson JA, Hutt DF, Lachmann HJ, Whelan CJ, Wechalekar AD, Herrey AS, Gillmore JD, Hawkins PN, Moon JC. Differential myocyte responses in patients with cardiac transthyretin amyloidosis and light-chain amyloidosis: a cardiac MR imaging study. Radiology. 2015;277(2): 388-97.

76. Oda S, Utsunomiya D, Nakaura T, Yuki H, Kidoh M, Morita K, Takashio S, Yamamuro M, Izumiya Y,
Hirakawa K, Ishida T, Tsujita K, Ueda M, Yamashita T, Ando Y, Hata H, Yamashita Y. Identification and assessment of cardiac amyloidosis by myocardial strain analysis of cardiac magnetic resonance imaging. Circ J. 2017;81(7):1014-21.

77. Treibel TA, Bandula S, Fontana M, White SK, Gilbertson JA, Herrey AS, Gillmore JD, Punwani S, Hawkins PN, Taylor SA, Moon JC. Extracellular volume quantification by dynamic equilibrium cardiac computed tomography in cardiac amyloidosis. J Cardiovasc Comput Tomogr. 2015;9(6): 585-92.

78. Chevance V, Damy T, Tacher V, Legou F, Ridouani F, Luciani A, Kobeiter H, Rahmouni A, Deux JF. Myocardial iodine concentration measurement using dual-energy computed tomography for the diagnosis of cardiac amyloidosis: a pilot study. Eur Radiol. 2018;28(2):816-23.

79. Khalique Z, Ferreira PF, Scott AD, Nielles-Vallespin S, Martinez-Naharro A, Fontana M, Hawkins P, Firmin DN, Pennell DJ. Diffusion tensor cardiovascular magnetic resonance in cardiac amyloidosis. Circ Cardiovasc Imaging. 2020;13(5):e009901.

80. Kollmer J, Hund E, Hornung B, Hegenbart U, Schönland SO, Kimmich C, Kristen AV, Purrucker J, Röcken C, Heiland S, Bendszus M, Pham M. In vivo detection of nerve injury in familial amyloid polyneuropathy by magnetic resonance neurography. Brain. 2015;138(Pt 3):549-62.

81. Kollmer J, Sahm F, Hegenbart U, Purrucker JC, Kimmich C, Schönland SO, Hund E, Heiland S, Hayes JM, Kristen AV, Röcken C, Pham M, Bendszus M, Weiler M. Sural nerve injury in familial amyloid polyneuropathy: MR neurography vs clinicopathologic tools. Neurology. 2017;89(5):475-84.

82. Castano A, Haq M, Narotsky DL, Goldsmith J, Weinberg RL, Morgenstern R, Pozniakoff T, Ruberg FL, Miller EJ, Berk JL, Dispenzieri A, Grogan M, Johnson G, Bokhari S, Maurer MS. Multicenter study of planar technetium $99 \mathrm{~m}$ pyrophosphate cardiac imaging: predicting survival for patients with ATTR cardiac amyloidosis. JAMA Cardiol. 2016;1(8):880-9.

83. Gillmore JD, Maurer MS, Falk RH, Merlini G, Damy T, Dispenzieri A, Wechalekar AD, Berk JL, Quarta CC, Grogan M, Lachmann HJ, Bokhari S, Castano A, Dorbala S, Johnson GB, Glaudemans AW, Rezk T, Fontana M, Palladini G, Milani P, Guidalotti PL, Flatman K, Lane T, Vonberg FW, Whelan CJ, Moon JC, Ruberg FL, Miller EJ, Hutt DF, Hazenberg BP, Rapezzi C, Hawkins PN. Nonbiopsy diagnosis of cardiac transthyretin amyloidosis. Circulation. 2016;133(24):2404-12. 
84. Wieland DM, Brown LE, Rogers WL, Worthington KC, Wu JL, Clinthorne NH, Otto CA, Swanson DP, Beierwaltes WH. Myocardial imaging with a radioiodinated norepinephrine storage analog. J Nucl Med. 1981;22(1):22-31.

85. Schofer J, Spielmann R, Schuchert A, Weber K, Schlüter M. Iodine-123 meta-iodobenzylguanidine scintigraphy: a noninvasive method to demonstrate myocardial adrenergic nervous system disintegrity in patients with idiopathic dilated cardiomyopathy. J Am Coll Cardiol. 1988;12(5):1252-8.

86. Ando Y, Obayashi K, Tanaka Y, Tsuji T, Uchino M, Takahashi M, Ando M. Radiolabelled metaiodobenzylguanidine in assessment of autonomic dysfunction. Lancet. 1994;343(8903):984-5.

87. Rosengren S, Skibsted Clemmensen T, Tolbod L, Granstam SO, Eiskjær H, Wikström G, Vedin O, Kero T, Lubberink M, Harms HJ, Flachskampf FA, Baron T, Carlson K, Mikkelsen F, Antoni G, Frost Andersen N, Hvitfeldt Poulsen S, Sörensen J. Diagnostic accuracy of $\left[{ }^{11} \mathrm{C}\right] \mathrm{PIB}$ positron emission tomography for detection of cardiac amyloidosis. JACC Cardiovasc Imaging. 2020;13(6):1337-47.

88. Law WP, Wang WY, Moore PT, Mollee PN, Ng AC. Cardiac amyloid imaging with 18F-Florbetaben PET: a pilot study. J Nucl Med. 2016;57(11):1733-9.

89. Park MA, Padera RF, Belanger A, Dubey S, Hwang DH, Veeranna V, Falk RH, Di Carli MF, Dorbala S. 18F-florbetapir binds specifically to myocardial light chain and transthyretin amyloid deposits: autoradiography study. Circ Cardiovasc Imaging. 2015;8(8):e002954.

90. Sekijima Y, Yazaki M, Oguchi K, Ezawa N, Yoshinaga $T$, Yamada $M$, Yahikozawa $H$, Watanabe $M$, Kametani F, Ikeda S. Cerebral amyloid angiopathy in posttransplant patients with hereditary ATTR amyloidosis. Neurology. 2016;87(8):773-81.

91. Ezawa N, Katoh N, Oguchi K, Yoshinaga T, Yazaki M, Sekijima Y. Visualization of multiple organ amyloid involvement in systemic amyloidosis using ${ }^{11} \mathrm{C}-\mathrm{PiB}$ PET imaging. Eur J Nucl Med Mol Imaging. 2018;45(3):452-61.

92. Takasone K, Katoh N, Takahashi Y, Abe R, Ezawa N, Yoshinaga T, Yanagisawa S, Yazaki M, Oguchi K, Koyama J, Sekijima Y. Non-invasive detection and differentiation of cardiac amyloidosis using ${ }^{99 \mathrm{~m}} \mathrm{Tc}$ pyrophosphate scintigraphy and ${ }^{11} \mathrm{C}$-Pittsburgh compound B PET imaging. Amyloid. 2020;27(4): 266-74.

93. Miyazaki Y, Koike H, Akane A, Shibata Y, Nishiwaki K, Sobue G. Spinal cord stimulation markedly ameliorated refractory neuropathic pain in transthyretin Val30Met familial amyloid polyneuropathy. Amyloid. 2011;18(2):87-90.

94. Ando E, Ando Y, Okamura R, Uchino M, Ando M, Negi A. Ocular manifestations of familial amyloidotic polyneuropathy type I: long-term follow up. Br J Ophthalmol. 1997;81(4):295-8.

95. Ando Y, Ohlsson PI, Suhr O, Nyhlin N, Yamashita T, Holmgren G, Danielsson A, Sandgren O, Uchino M, Ando M. A new simple and rapid screening method for variant transthyretin-related amyloidosis. Biochem Biophys Res Commun. 1996;228(2):480-3.

96. Holmgren G, Steen L, Ekstedt J, Groth CG, Ericzon BG, Eriksson S, Andersen O, Karlberg I, Nordén G, Nakazato M, Hawkins P, Richardson S, Pepys M. Biochemical effect of liver transplantation in two Swedish patients with familial amyloidotic polyneuropathy (FAP-met30). Clin Genet. 1991;40(3):242-6.

97. Yamashita T, Ando Y, Okamoto S, Misumi Y, Hirahara T, Ueda M, Obayashi K, Nakamura M, Jono H, Shono M, Asonuma K, Inomata Y, Uchino M. Longterm survival after liver transplantation in patients with familial amyloid polyneuropathy. Neurology. 2012;78(9):637-43.

98. Yazaki M, Mitsuhashi S, Tokuda T, Kametani F, Takei YI, Koyama J, Kawamorita A, Kanno H, Ikeda SI. Progressive wild-type transthyretin deposition after liver transplantation preferentially occurs onto myocardium in FAP patients. Am J Transplant. $2007 ; 7(1): 235-42$.

99. Liepnieks JJ, Zhang LQ, Benson MD. Progression of transthyretin amyloid neuropathy after liver transplantation. Neurology. 2010;75(4):324-7.

100. Koike H, Hashimoto R, Tomita M, Kawagashira Y, Iijima M, Nakamura T, Watanabe $H$, Kamei $H$, Kiuchi T, Sobue G. Impact of aging on the progression of neuropathy after liver transplantation in transthyretin Val30Met amyloidosis. Muscle Nerve. 2012;46(6):964-70.

101. Ericzon BG, Wilczek HE, Larsson M, Wijayatunga $P$, Stangou A, Pena JR, Furtado E, Barroso E, Daniel J, Samuel D, Adam R, Karam V, Poterucha J, Lewis D, Ferraz-Neto BH, Cruz MW, Munar-Ques M, Fabregat J, Ikeda S, Ando Y, Heaton N, Otto G, Suhr O. Liver transplantation for hereditary transthyretin amyloidosis: after 20 years still the best therapeutic alternative? Transplantation. 2015;99(9):1847-54.

102. Koike H, Fukami Y, Nishi R, Kawagashira Y, Iijima M, Sobue G, Katsuno M. Clinicopathological spectrum and recent advances in the treatment of hereditary transthyretin amyloidosis. Neurol Clin Neurosci. 2019;7(4):166-73. 
103. Ando Y, Terazaki H, Nakamura M, Ando E, Haraoka K, Yamashita T, Ueda M, Okabe H, Sasaki Y, Tanihara $\mathrm{H}$, Uchino $\mathrm{M}$, Inomata $\mathrm{Y}$. A different amyloid formation mechanism: de novo oculoleptomeningeal amyloid deposits after liver transplantation. Transplantation. 2004;77(3):345-9.

104. Peterson SA, Klabunde T, Lashuel HA, Purkey $H$, Sacchettini JC, Kelly JW. Inhibiting transthyretin conformational changes that lead to amyloid fibril formation. Proc Natl Acad Sci USA. 1998;95(22): 12956-60.

105. Miller SR, Sekijima Y, Kelly JW. Native state stabilization by NSAIDs inhibits transthyretin amyloidogenesis from the most common familial disease variants. Lab Investig. 2004;84(5):545-52.

106. Obici L, Adams D. Acquired and inherited amyloidosis: knowledge driving patients' care. J Peripher Nerv Syst. 2020;25(2):85-101.

107. Coelho T, Maia LF, da Silva AM, Cruz MW, PlantéBordeneuve V, Lozeron P, Suhr OB, Campistol JM, Conceição IM, Schmidt HH, Trigo P, Kelly JW, Labaudinière R, Chan J, Packman J, Wilson A, Grogan DR. Tafamidis for transthyretin familial amyloid polyneuropathy: a randomized, controlled trial. Neurology. 2012;79(8):785-92.

108. Barroso FA, Judge DP, Ebede B, Li H, Stewart M, Amass L, Sultan MB. Long-term safety and efficacy of tafamidis for the treatment of hereditary transthyretin amyloid polyneuropathy: results up to 6 years. Amyloid. 2017;24(3):194-204.

109. Merlini G, Coelho T, Waddington Cruz M, Li H, Stewart M, Ebede B. Evaluation of mortality during long-term treatment with tafamidis for transthyretin amyloidosis with polyneuropathy: clinical trial results up to 8.5 years. Neurol Ther. 2020;9(1): 105-15.

110. Maurer MS, Schwartz JH, Gundapaneni B, Elliott PM, Merlini G, Waddington-Cruz M, Kristen AV, Grogan M, Witteles R, Damy T, Drachman BM, Shah SJ, Hanna M, Judge DP, Barsdorf AI, Huber P, Patterson TA, Riley S, Schumacher J, Stewart M, Sultan MB, Rapezzi C, ATTR-ACT Study Investigators. Tafamidis treatment for patients with transthyretin amyloid cardiomyopathy. N Engl J Med. 2018;379(11):1007-16.

111. Hanna M, Damy T, Grogan M, Stewart M, Gundapaneni B, Patterson TA, Schwartz JH, Sultan MB, Maurer MS. Impact of tafamidis on health-related quality of life in patients with transthyretin amyloid cardiomyopathy (from the Tafamidis in Transthyretin Cardiomyopathy Clinical Trial). Am J Cardiol. 2021;15(141):98-105.
112. Berk JL, Suhr OB, Obici L, Sekijima Y, Zeldenrust SR, Yamashita T, Heneghan MA, Gorevic PD, Litchy WJ, Wiesman JF, Nordh E, Corato M, Lozza A, Cortese A, Robinson-Papp J, Colton T, Rybin DV, Bisbee AB, Ando Y, Ikeda S, Seldin DC, Merlini G, Skinner M, Kelly JW, Dyck PJ, Diflunisal Trial Consortium. Repurposing diflunisal for familial amyloid polyneuropathy: a randomized clinical trial. JAMA. 2013;310(24):2658-67.

113. Benson MD, Kluve-Beckerman B, Zeldenrust SR, Siesky AM, Bodenmiller DM, Showalter AD, Sloop KW. Targeted suppression of an amyloidogenic transthyretin with antisense oligonucleotides. Muscle Nerve. 2006;33(5):609-18.

114. Adams D, Gonzalez-Duarte A, O'Riordan WD, Yang CC, Ueda M, Kristen AV, Tournev I, Schmidt HH, Coelho T, Berk JL, Lin KP, Vita G, Attarian S, PlantéBordeneuve V, Mezei MM, Campistol JM, Buades J, Brannagan TH III, Kim BJ, Oh J, Parman Y, Sekijima Y, Hawkins PN, Solomon SD, Polydefkis M, Dyck PJ, Gandhi PJ, Goyal S, Chen J, Strahs AL, Nochur SV, Sweetser MT, Garg PP, Vaishnaw AK, Gollob JA, Suhr OB. Patisiran, an RNAi therapeutic, for hereditary transthyretin amyloidosis. $\mathrm{N}$ Engl J Med. 2018;379(1):11-21.

115. Minamisawa M, Claggett B, Adams D, Kristen AV, Merlini G, Slama MS, Dispenzieri A, Shah AM, Falk RH, Karsten V, Sweetser MT, Chen J, Riese R, Vest J, Solomon SD. Association of Patisiran, an RNA interference therapeutic, with regional left ventricular myocardial strain in hereditary transthyretin amyloidosis: the APOLLO study. JAMA Cardiol. 2019;4(5):466-72.

116. Solomon SD, Adams D, Kristen A, Grogan M, González-Duarte A, Maurer MS, Merlini G, Damy T, Slama MS, Brannagan TH III, Dispenzieri A, Berk JL, Shah AM, Garg P, Vaishnaw A, Karsten V, Chen J, Gollob J, Vest J, Suhr O. Effects of Patisiran, an RNA interference therapeutic, on cardiac parameters in patients with hereditary transthyretin-mediated amyloidosis. Circulation. 2019;139(4):431-43.

117. Coelho T, Adams D, Conceição I, Waddington-Cruz M, Schmidt HH, Buades J, Campistol J, Berk JL, Polydefkis M, Wang JJ, Chen J, Sweetser MT, Gollob J, Suhr OB. A phase II, open-label, extension study of long-term patisiran treatment in patients with hereditary transthyretin-mediated (hATTR) amyloidosis. Orphanet J Rare Dis. 2020;15(1):179.

118. Adams D, Polydefkis M, González-Duarte A, Wixner J, Kristen AV, Schmidt HH, Berk JL, Losada López IA, Dispenzieri A, Quan D, Conceição IM, Slama MS, Gillmore JD, Kyriakides T, Ajroud-Driss S, Waddington-Cruz M, Mezei MM, Planté-Bordeneuve V, Attarian S, Mauricio E, Brannagan TH III, Ueda M, Aldinc E, Wang JJ, White MT, Vest J, Berber E, Sweetser MT, Coelho T, Patisiran Global 
OLE study group. Long-term safety and efficacy of patisiran for hereditary transthyretin-mediated amyloidosis with polyneuropathy: 12-month results of an open-label extension study. Lancet Neurol. 2021;20(1):49-59.

119. Benson MD, Waddington-Cruz M, Berk JL, Polydefkis M, Dyck PJ, Wang AK, Planté-Bordeneuve V, Barroso FA, Merlini G, Obici L, Scheinberg M, Brannagan TH III, Litchy WJ, Whelan C, Drachman BM, Adams D, Heitner SB, Conceição I, Schmidt $\mathrm{HH}$, Vita G, Campistol JM, Gamez J, Gorevic PD, Gane E, Shah AM, Solomon SD, Monia BP, Hughes SG, Kwoh TJ, McEvoy BW, Jung SW, Baker BF, Ackermann EJ, Gertz MA, Coelho T. Inotersen treatment for patients with hereditary transthyretin amyloidosis. N Engl J Med. 2018;379(1):22-31.

120. Brannagan TH, Wang AK, Coelho T, Waddington Cruz M, Polydefkis MJ, Dyck PJ, Plante-Bordeneuve V, Berk JL, Barroso F, Merlini G, Conceição I, Hughes SG, Kwoh J, Jung SW, Guthrie S, Pollock M, Benson MD, Gertz M, NEURO-TTR open-label extension investigators. Early data on long-term efficacy and safety of inotersen in patients with hereditary transthyretin amyloidosis: a 2-year update from the open-label extension of the NEURO-TTR trial. Eur J Neurol. 2020;27(8):1374-81.

121. Dasgupta NR, Rissing SM, Smith J, Jung J, Benson MD. Inotersen therapy of transthyretin amyloid cardiomyopathy. Amyloid. 2020;27(1):52-8.

122. Viney NJ, Guo S, Tai LJ, Baker BF, Aghajan M, Jung SW, Yu RZ, Booten S, Murray H, Machemer T, Burel S, Murray S, Buchele G, Tsimikas S, Schneider E, Geary RS, Benson MD, Monia BP. Ligand conjugated antisense oligonucleotide for the treatment of transthyretin amyloidosis: preclinical and phase 1 data. ESC Heart Fail. 2021;8(1):652-61.

123. Coelho T, Ando Y, Benson MD, Berk JL, Waddington-Cruz M, Dyck PJ, Gillmore JD, Khella SL, Litchy WJ, Obici L, Monteiro C, Tai LJ, Viney NJ, Buchele G, Brambatti M, Jung SW, St L O’Dea L, Tsimikas S, Schneider E, Geary RS, Monia BP, Gertz M. Design and rationale of the global phase 3 NEUROTTRansform study of antisense oligonucleotide AKCEA-TTR-L $\mathrm{Rx}_{\mathrm{Rx}}$ (ION-682884-CS3) in hereditary transthyretin-mediated amyloid polyneuropathy. Neurol Ther. 2021;10(1):375-89.

124. Buxbaum JN. Treatment of hereditary and acquired forms of transthyretin amyloidosis in the era of personalized medicine: the role of randomized controlled trials. Amyloid. 2019;26(2):55-65.

125. Guidon AC, Amato AA. COVID-19 and neuromuscular disorders. Neurology. 2020;94(22):959-69.

126. Sayer G, Horn EM, Farr MA, Axsom K, Kleet A, Gjerde C, Latif F, Sobol I, Kelley N, Lancet E, Halik C, Takeda K, Naka Y, Yuzefpolskaya M, Kumaraiah D, Colombo PC, Maurer MS, Uriel N. Transition of a large tertiary heart failure program in response to the COVID-19 pandemic: changes that will endure. Circ Heart Fail. 2020;13(9):e007516.

127. Driggin E, Madhavan MV, Bikdeli B, Chuich T, Laracy J, Biondi-Zoccai G, Brown TS, Der Nigoghossian C, Zidar DA, Haythe J, Brodie D, Beckman JA, Kirtane AJ, Stone GW, Krumholz HM, Parikh SA. Cardiovascular considerations for patients, health care workers, and health systems during the COVID-19 pandemic. J Am Coll Cardiol. 2020;75(18):2352-71.

128. Gallo Marin B, Aghagoli G, Lavine K, Yang L, Siff EJ, Chiang SS, Salazar-Mather TP, Dumenco L, Savaria MC, Aung SN, Flanigan T, Michelow IC. Predictors of COVID-19 severity: a literature review. Rev Med Virol. 2021;31(1):1-10.

129. Belli LS, Duvoux C, Karam V, Adam R, CuervasMons V, Pasulo L, Loinaz C, Invernizzi F, Patrono D, Bhoori S, Ciccarelli O, Morelli MC, Castells L, Lopez-Lopez V, Conti S, Fondevila C, Polak W. COVID-19 in liver transplant recipients: preliminary data from the ELITA/ELTR registry. Lancet Gastroenterol Hepatol. 2020;5(8):724-5.

130. Dumortier J, Duvoux C, Roux O, Altieri M, Barraud H, Besch C, Caillard S, Coilly A, Conti F, Dharancy S, Durand F, Francoz C, Garaix F, Houssel-Debry P, Kounis I, Lassailly G, Laverdure N, Leroy V, Mallet M, Mazzola A, Meunier L, Radenne S, Richardet JP, Vanlemmens C, Hazzan M, Saliba F, French Solid Organ Transplant COVID Registry; Groupe de Recherche Français en Greffe de Foie (GReF2). Covid-19 in liver transplant recipients: the French SOT COVID registry. Clin Res Hepatol Gastroenterol. 2021;45(4):101639.

131. Webb GJ, Moon AM, Barnes E, Barritt AS, Marjot T. Age and comorbidity are central to the risk of death from COVID-19 in liver transplant recipients. J Hepatol. (In press). 